Archived version from NCDOCKS Institutional Repository http://libres.uncg.edu/ir/asu/

\title{
Appalachľan
}

B O O N E, N O R T H C A R O L I N A

\section{Members Matter In Team Training: Multilevel And Longitudinal Relationships Between Goal Orientation, Self-Regulation, And Team Outcomes}

\author{
By: Erich C. Dierdorff and J. Kemp Ellington
}

\begin{abstract}
Longitudinal data from 338 individuals across 64 teams in a simulation-based team-training context were used to examine the effects of dispositional goal orientation on self-regulated learning (self-efficacy and metacognition). Team goal orientation compositions, as reflected by average goal orientations of team members, were examined for moderating effects on these individual-level relationships. Finally, individual-level self-regulation was investigated for its influence on multiple team-level outcomes across time. Results showed generally positive effects of learning goal orientation and negative effects of avoid performance and prove performance goal orientations on rates of self-regulation during team training. However, several of these individual-level relationships were moderated by team goal orientation composition. The importance of selfregulation in teams was displayed by results showing the average level of self-regulation among a team's members over time was positively associated with team efficacy, team cooperation quality, and team decision making.
\end{abstract}

Dierdorff, E. C. and Ellington, J. K. (2012), Members Matter in Team Training: Multilevel and Longitudinal Relationships Between Goal Orientation, Self-Regulation, and Team Outcomes. Personnel Psychology, 65: 661-703. doi:10.1111/j.1744-6570.2012.01255.x. Publisher version of record available at: https:// onlinelibrary.wiley.com/doi/10.1111/j.1744-6570.2012.01255.x 


\title{
Members Matter In Team Training: Multilevel And Longitudinal Relationships Between Goal Orientation, Self-Regulation, And Team Outcomes
}

\author{
ERICH C. DIERDORFF \\ DePaul University \\ J. KEMP ELLINGTON \\ Illinois Institute of Technology
}

\begin{abstract}
Longitudinal data from 338 individuals across 64 teams in a simulationbased team-training context were used to examine the effects of dispositional goal orientation on self-regulated learning (self-efficacy and metacognition). Team goal orientation compositions, as reflected by average goal orientations of team members, were examined for moderating effects on these individual-level relationships. Finally, individual-level self-regulation was investigated for its influence on multiple team-level outcomes across time. Results showed generally positive effects of learning goal orientation and negative effects of avoid performance and prove performance goal orientations on rates of self-regulation during team training. However, several of these individual-level relationships were moderated by team goal orientation composition. The importance of self-regulation in teams was displayed by results showing the average level of self-regulation among a team's members over time was positively associated with team efficacy, team cooperation quality, and team decision making.
\end{abstract}

The prevalent use of teams as an organizing structure of work in today’s organizations is well documented (Guzzo \& Dickson, 1996; Turner, 2001). Concomitant with this prevalence is a burgeoning literature regarding training in team contexts. Yet, with very few exceptions (e.g., Chen, Thomas, \& Wallace, 2005; DeShon, Kozlowski, Schmidt, Milner, \& Weichmann, 2004) the extant research has primarily focused on teamlevel learning outcomes (e.g., team performance, team mental models, etc.) to the neglect of individual-level learning within these team-training contexts. This omission is unfortunate because team learning is necessarily

We thank James Belohlav for his assistance with data collection. An earlier version of this manuscript was presented at the 71st Annual Meeting of the Academy of Management, San Antonio, TX.

Correspondence and requests for reprints should be addressed to Erich C. Dierdorff, Driehaus College of Business, Department of Management, DePaul University, 1 East Jackson Boulevard, Chicago, IL 60604-2287; edierdor@depaul.edu 
dependent upon the acquisition of training by a team's individual members (Day et al., 2005; Ellis et al., 2003). That is, team-level training outcomes are in part the collective consequences of individual-level learning, and understanding learning in team contexts requires an examination of individual and team variables on learning processes (DeShon et al., 2004). Although training researchers have begun to investigate these different learning processes, examinations of learning outcomes as they develop over time for both team members and teams still remain an important yet largely undeveloped area of the team-training literature (Chen \& Klimoski, 2007).

In this study, we examine the multilevel and longitudinal influences of dispositional goal orientation on individual-level self-regulation during team training and the effects of this self-regulation on team-level outcomes. Substantial cross-sectional research has investigated the effects of goal orientation (Payne, Youngcourt, \& Beaubien, 2007), yet studies of how goal orientation influences individual learning over time or in team contexts are comparatively rare. This paucity represents an important limitation in the goal orientation and team-training literatures because both individual learning and team performance are widely conceptualized as dynamic processes (Ilgen, Hollenbeck, Johnson, \& Jundt, 2005; Weiss, 1990). Moreover, team training naturally entails learning within team settings that create unique social contexts compared to nonteam settings, and these contexts are thought to impact the effects of dispositional goal orientation in particular (Porter, 2008). Finally, as Chen and Klimoski (2007) noted in their review of the training and development literature, relatively little is known about the interplay between individual-level and team-level learning processes and outcomes.

With these needs in mind, we investigated individual differences in learning, prove performance, and avoid performance dispositional goal orientations for their effects on changes in self-regulated learning outcomes over time (metacognition and self-efficacy). We further explored the cross-level moderating effects of team-level goal orientation composition (mean dispositional goal orientation across a team's members) on these individual-level relationships. Last, because team-training results in team outcomes that are cognitive, behavioral/skill-based, and attitudinal in nature (Salas et al., 2008), we examined whether or not selfregulation among team members exerts bottom-up influences on multiple team-level outcomes, including cognitive outcomes (team strategic decision-making), behavioral outcomes (team cooperation quality), and affective outcomes (team efficacy).

In the paragraphs that follow, we first build hypotheses pertaining to the individual-level relationships between goal orientation and self-regulation over time. Next, we discuss how teams represent discrete social contexts, 
reflected in a team's composition with respect to the goal orientation of its members, that moderate individual-level self-regulation over time. Finally, we describe how individual-level self-regulation is likely to translate to team-level outcomes.

\section{Goal Orientation and Self-Regulation in Team Training}

Self-regulation is a central factor in skill acquisition and learning (Kanfer \& Ackerman, 1989; Zimmerman, 1990) and refers to processes that "enable an individual to guide his/her goal-directed activities over time and across changing circumstances" (Karoly, 1993, p. 25). Engaging in self-regulation entails activities such as planning, self-monitoring, and self-evaluation (Bandura, 1991; Kanfer \& Ackerman, 1989). With regard to training in general, self-regulation is important because of its dynamic nature (i.e., fluctuates over time) and its impact on motivation and ultimately performance (Bell \& Kozlowski, 2010; Beier \& Kanfer, 2010). Self-regulation is important to team training as well, even though the primary focus is on team-level outcomes, because team-level functioning is contingent on individual team members' learning processes.

Among the key variables reflecting self-regulatory processes are concepts such as metacognition and self-efficacy (Gully \& Chen, 2010; Kozlowski et al., 2001). Metacognition is "thinking about one's thinking” (Flavell, 1979) and involves assessing and adjusting one's learning strategy with regard to task mastery (Cannon-Bowers, Salas, \& Milham, 2003; Schmidt \& Ford, 2003). Self-efficacy is the belief in one's capability to perform a particular task or meet a set of situational demands (Bandura, 1982, 1997) and represents an individual's affective selfreaction to learning. Both of these concepts reflect self-regulation because they pertain to a learner's self-monitoring and self-evaluation. In this study, we investigated individuals' dynamic self-regulation as shown through changes over time in metacognition and self-efficacy.

One individual characteristic thought to influence self-regulatory processes over time is goal orientation (Button, Mathieu, \& Zajac, 1996). Goal orientations refer to individual preferences for different types of goals in achievement contexts (Dweck, 1986; Dweck \& Leggett, 1988) and are typically operationalized in three forms (Day, Yeo, \& Radosevich, 2003; VandeWalle \& Cummings, 1997): learning goal orientation (LGO), prove performance goal orientation (PPGO), and, avoid performance goal orientation (APGO). Although situations may be constructed to induce performance or learning goals, goal orientation can also be conceptualized as a relatively stable disposition (Attenweiler \& Moore, 2006; Button et al., 1996). As such, different goal orientations reflect different patterns of cognition and behavior across situations and time (DeShon 
\& Gillespie, 2005). This suggests the effects of goal orientation on selfregulation that have been demonstrated in cross-sectional research, such as those found for metacognition and self-efficacy (Payne et al., 2007; Schmidt \& Ford, 2003), are likely to accrue over time as the pattern of behavior and cognition associated with a particular goal orientation emerge. This expectation is also congruent with research supporting the reciprocal, cumulative nature of self-regulation (Schunk, 1990). In this study, an accumulation of effects would be reflected in different rates of change in self-regulation over time associated with different individual goal orientations.

LGO is characterized by preferences to develop competence through acquiring new skills and knowledge (Bouffard, Boisvert, Vezeau, \& Larouche, 1995; VandeWalle \& Cummings, 1997). Individuals high in LGO seek out challenges, maintain motivation under difficult conditions or failure, focus on learning from experience, and seek to achieve a sense of mastery (Ames, 1992; VandeWalle, Cron, \& Slocum, 2001). LGO also positively influences the amount of effort and persistence individuals dedicate to requisite learning tasks (Brown, 2001; Fisher \& Ford, 1998). Such evidence suggests that LGO promotes a more active engagement throughout the learning process. Yet, the few studies that have examined longitudinal effects of LGO have not provided supportive evidence. For example, Yeo and Neal (2004) and Chen and Mathieu (2008) failed to find significant effects for LGO on rates of performance, although the effects in both studies trended positive. Important to note is that these studies did not examine self-regulatory outcomes but rather focused on declarative or procedural knowledge acquisition through multiple-choice exams and simulations (e.g., Air Traffic Control task and Money Trail). Self-regulation is often viewed as an antecedent to knowledge acquisition (Bell \& Kozlowski, 2010), suggesting that a specific focus on selfregulatory outcomes could help clarify the effects of dispositional LGO on longitudinal learning processes.

There are reasons to expect LGO to exert longitudinal influences on self-regulatory outcomes such as metacognition and self-efficacy. For example, resource allocation theory purports that allocation of resources to on-task activities will promote learning (Kanfer \& Ackerman, 1989), and high LGO individuals tend to have a more inward, task-oriented focus (Elliot, Shell, Henry, \& Maier, 2005; Yeo, Loft, Xiao, \& Kiewitz, 2009). Furthermore, high LGO has been linked to an increased use of learning strategies to gain task mastery (Payne et al., 2007) and greater persistence in overcoming obstacles in the face of learning difficulties (VandeWalle et al., 2001). Such research and theory suggest that high LGO individuals will dedicate more resources to planning and monitoring their progress toward task mastery, as well as to adjusting their approaches to better deal 
with learning challenges compared to low LGO individuals. Adjusting learning strategies over time requires increased metacognition as one must monitor and adapt to the successive tasks that are presented during training. In addition, successfully accomplishing these tasks is a key factor that affects the continuing development of beliefs about performance capability (i.e., change in self-efficacy). Therefore, the adaptive response patterns reflected by high LGO should enhance individuals' self-regulation over time.

Hypothesis 1: LGO is positively related to individual-level rates of change in self-efficacy and metacognition during team training

Performance-oriented learners tend to think that performance reflects ability (Schraw, Horn, Thorndike-Christ, \& Bruning, 1995) and prefer normative standards to evaluate mastery (Diener \& Dweck, 1978). Learners high in PPGO have strong desires to demonstrate their competence relative to others (VandeWalle, 1997). Results from cross-sectional research have been mixed, with some evidence showing PPGO is associated with increased use of learning strategies (Payne et al., 2007) and other evidence showing PPGO is linked to lower motivation (Fisher \& Ford, 1998) and higher learner anxiety (Chen, Gully, Whiteman, \& Kilcullen, 2000).

With regard to the longitudinal effects of PPGO, an increased emphasis on demonstrating competence and having an outcome-oriented focus (exemplified by high PPGO) can drain the cognitive resources needed for successful learning (Kanfer \& Ackerman, 1989). One reason for this detrimental effect is that high PPGO shifts attention away from core task activities (Beier \& Kanfer, 2010; Yeo et al., 2009), and over time this would result in less task-focused self-regulation across successive learning tasks. As Chen and Mathieu (2008) argued, a "concern for demonstrating one's skill, rather than learning or developing skills, can come at the expense of learning subtle aspects of a task domain and developing appropriate performance strategies" (p. 24). Although these authors did not find a significant relationship between PPGO and performance over time, the association trended in the predicted direction (i.e., negative). Yeo and Neal (2004), however, did find that PPGO was associated with lower rates of skill acquisition. Such theory and evidence suggest that the response patterns indicative of high PPGO individuals will relate to less effective monitoring and planning needed for successful task mastery during training. Therefore, we expected high PPGO learners would have lower rates of self-regulation. 
Hypothesis 2: PPGO is negatively related to individual-level rates of change in self-efficacy and metacognition during team training.

Similar to high PPGO individuals, those high in APGO focus attention on external information about their relative competence. However, high APGO individuals have strong preferences to avoid negative information about competence (Elliot \& Harackiewicz, 1996). Some have suggested high APGO is akin to a fear of failure within performance or learning settings (Elliot \& Church, 1997). Cross-sectional research shows that high APGO individuals engage in less proactive behavior useful for selfdevelopment (Porath \& Bateman, 2006), seek less performance-related feedback (VandeWalle \& Cummings, 1997), and demonstrate lower levels of learning and academic performance (Payne et al., 2007).

One reason for the deleterious effects of APGO on learning is its association with avoid-related processes, which reflect desires to withdraw from goal-directed behavior (Elliot et al., 2005). Similar to high PPGO individuals, attentional resources are shifted away from task mastery, but in the case of high APGO these resources are not rededicated toward approach-related tendencies. Thus, high APGO individuals are likely to experience more task distractions (Rawsthorne \& Elliot, 1999) and more cognitive "disorganization," both of which describe a lack of establishing and maintaining a structured and organized approach to learning (Elliot, McGregor, \& Gable, 1999). The fear of displaying incompetence to others is also likely to decrease an individual's motivation to practice and master the learning content (Brown, 2001), which detracts from developing selfefficacy. When collectively considered, this theory and evidence suggests the avoidant response patterns that typify high APGO learners are associated with lower levels of, and less focused, self-regulation with regard to task mastery. Over the course of a training event, these maladaptive response patterns are likely to accrue as individuals continually engage in avoidant actions over successive learning tasks. We thus expected APGO to have deleterious effects on rates of change in metacognition and selfefficacy.

Hypothesis 3: APGO is negatively related to individual-level rates of
change in self-efficacy and metacognition during team
training. Goal Orientation Composition as Team Context

Participating in team training involves individuals learning in assigned teams alongside fellow team members. As such, individual-level learning in team training occurs within discrete social contexts linked to team 
membership, where social context represents the interpersonal relationships and contingencies in a given setting (Johns, 2006; Morgeson \& Dierdorff, 2010). This suggests that examining a team's membership or composition is one way to delineate the social context created by that team. Team composition is generally defined as the combination of team members' attributes (Mohammed, Hamilton, \& Lim, 2008), and team compositions are known to affect team processes and outcomes (Bell, 2007). These effects emerge in a "bottom-up" process whereby individual characteristics combine to create a descriptive property of the team as a whole (Kozlowski \& Klein, 2000). Consistent with arguments that team contexts encourage or discourage particular team member behaviors (Hackman, 1992), the influences of team composition result in part because individual differences affect the manner with which team members will interact and approach required tasks when learning in teams.

Different team goal orientation compositions are likely associated with different patterns of behavior common among team members. As Porter (2005) noted, examining goal orientation as a team-level compositional variable is a "useful way of describing the inputs of the individual members who make up a team" (p. 816). For example, teams composed of high LGO members are likely to collectively engage in more planning (Mehta, Feild, Armenakis, \& Mehta, 2009) and positive teamwork behaviors such as backing-up behavior (Porter, 2005). Teams composed of high PPGO members are likely to display strong performance aspirations but less adjustment to change (Elliot \& Harackiewicz, 1996; LePine, 2005). Teams composed of high APGO members are much less likely to develop structured approaches to their own learning (Elliot et al., 1999) and thus are unlikely to provide cues for pursuing effective learning strategies (Dragoni, 2005). Finally, because research has shown team goal orientation composition as an important factor predicting team adaptation processes (LePine, 2005), the effects of team goal orientation composition are likely to be strongly evidenced in how learning processes unfold over time (e.g., changes in self-regulation). In this study, we operationalized goal orientation composition as a team's mean level of LGO, APGO, or PPGO among its members (Porter, 2008). ${ }^{1}$

Because goal orientation is expected to affect individual-level selfregulation, it is also likely that the goal orientation composition of teams will impact such learning processes. This expectation is consistent with interactional theory positing the importance of both personal and

\footnotetext{
${ }^{1}$ Although team goal orientation composition represents a team-level variable, it is not a collective construct, with "team" as the referent. This additive operationalization (Chan, 1998) and conceptualization is consistent with previous research examining team goal orientation compositions (LePine, 2005; Porter, 2005).
} 
TABLE 1

Linking Individual Goal Orientation and Team Goal Orientation Composition

\begin{tabular}{llll}
\hline \hline \multirow{2}{*}{$\begin{array}{l}\text { Individual goal } \\
\text { orientation }\end{array}$} & \multicolumn{3}{c}{ Team goal orientation composition } \\
\cline { 2 - 4 } LGO & Team mean LGO & Team mean PPGO & Team mean APGO \\
Parallelism & $\begin{array}{c}\text { Dissimilarity } \\
\text { (internal-external } \\
\text { referent) }\end{array}$ & $\begin{array}{c}\text { Dissimilarity } \\
\text { (internal-external } \\
\text { referent \& } \\
\text { approach-avoid) } \\
\text { Dissimilarity } \\
\text { (approach-avoid) }\end{array}$ \\
APGO & $\begin{array}{c}\text { Dissimilarity } \\
\text { (internal-external }\end{array}$ & Parallelism & Parallelism \\
& $\begin{array}{c}\text { (eferent) } \\
\text { Dissimilarity } \\
\text { (internal-external } \\
\text { referent \& } \\
\text { approach-avoid) }\end{array}$ & $\begin{array}{c}\text { Dissimilarity } \\
\text { (approach-avoid) }\end{array}$ & \\
\hline
\end{tabular}

Note. Forms of dissimilarity are shown in parentheses; LGO = learning goal orientation; PPGO = prove performance goal orientation; $\mathrm{APGO}=$ avoid performance goal orientation.

situational forces (Terborg, 1981). For example, the concept of trait relevance (Tett \& Guterman, 2000) specifies that contextual effects are more likely when corresponsive to particular individual characteristics. In the case of individual goal orientation and the goal orientations of others composing a team, such relevance stems from both the task at hand (i.e., learning within a training setting) and the fact that the focal compositional property of the team is "thematically connected" (Tett \& Burnett, 2003) to the individual-level construct (i.e., an individual's goal orientation in relation to other members' goal orientations). In addition, the interplay between person and situation with respect to self-regulation and goal-oriented behavior is congruent with motivated action theory (DeShon \& Gillespie, 2005), which stipulates that features of a situation increase the relevance of an individual's chronically active goals (e.g., failureavoidance goals).

One form of interplay between individual-level goal orientation and the learning contexts reflected by team goal orientation composition is when there is parallelism (see Table 1). Here, a team's mean goal orientation matches the individual-level goal orientation. In these parallel situations, the individual-level effects of different goal orientations are likely amplified. This accentuation, whether of positive or negative effects, is due in part to the congruence between individuals' dispositional tendencies and the cues and consequences that are provided and maintained in the team context. This prediction is consistent with motivated action theory (DeShon \& Gillespie, 2005) that posits individuals to have chronically active goals and structural similarity between the person and the context 
will increase the activation of goals relevant to that context. For example, the positive effects of LGO on individual-level learning are likely to be amplified in high mean LGO teams because the individual-level characteristics associated with LGO (e.g., persistence, effective resource allocation, etc.) are more likely to be mirrored in other team members and thus reinforced or "activated" in high mean LGO teams. Similarly, high mean PPGO teams are likely to regularly accentuate a focus on demonstrating competence externally, and such heightened collective emphasis on other-referenced performance is likely to further increase the selfregulation interference (Beier \& Kanfer, 2010) that is already problematic for high PPGO individuals. As for the negative effects of high APGO on individual-level learning, such effects are likely worsened in high mean APGO teams because these contexts provide few cues beneficial to selfregulation (e.g., feedback-seeking) yet offer ample cues that more saliently activate detrimental processes (e.g., avoiding a "threat" of failure).

Hypothesis 4a: The positive effects of LGO on individual-level selfregulation are amplified in teams with high mean levels of LGO.

Hypothesis $4 b$ : The negative effects of PPGO on individual-level selfregulation are amplified in teams with high mean levels of PPGO.

Hypothesis 4c: The negative effects of APGO on individual-level selfregulation are amplified in teams with high mean levels of APGO.

Another way to describe the interplay between individual-level goal orientation and team goal orientation composition is when there is dissimilarity. In these situations, there is a disparity between an individual's dispositional tendencies and the team's composition. With respect to goal orientation, dissimilarity could stem from an internal-external referent distinction or an approach-avoid distinction (see Table 1). The first form of dissimilarity is relevant to self-regulation because it represents the different targets for allocating one's cognitive resources (i.e., internally referenced task focus or externally referenced performance focus), and simultaneous attention to both of these targets is thought to interfere with effective resource allocation to learning (Zimmerman \& Kitsantas, 1997). The second form of dissimilarity influences self-regulation because it represents an incongruence that pertains to addressing performance discrepancies, namely, moving toward a goal to reduce discrepancy or moving away from a goal and thus amplifying discrepancy (Carver \& Scheier, 1998). It is important to note that dissimilarity can occur in one or both of these forms. Either way, dissimilarities are influential because they represent differences in how tasks are construed and the performance strategies 
that are emphasized by the individual compared to those emphasized by the team's composition. Research examining the effects of goal frame and goal content congruence on self-regulation further suggests that the influences of dissimilarity can be asymmetrical across different combinations as well (Kozlowski \& Bell, 2006).

During team training, high LGO individuals may experience dissimilarity of the internal-external referent type when learning in high mean PPGO teams. Here, incongruence arises between high LGO individuals' strong preferences to focus on internally referenced task mastery and team contexts where increased emphasis is placed on performance comparisons with others. Because individuals tend to have chronically active goals (DeShon \& Gillespie, 2005), this mismatch is likely to lead to frustration on the part of high LGO learners because other nonmastery goals become more relevant, such as those characterized by a heavy focus on simply outperforming other teams. Although high LGO individuals tend to engage in more self-regulation, the need to balance individual learning with overall team functioning during team training is also likely to strain the cognitive resources needed for self-regulation. This is primarily due to the tradeoff that exists when learners are forced to allocate their limited resources toward core task activities or toward performance comparisons (Seijts, Latham, Tasa, \& Latham, 2004). High LGO individuals in high mean APGO teams experience dissimilarity in both the internalexternal referent and approach-avoid forms. In this situation, not only would there be disparity in the way learning is construed (e.g., opportunity for deeper understanding vs. demonstrating competence) but also in the dominant response patterns reflected by the team's composition. In high mean APGO teams, members are more likely to engage in maladaptive actions that include seeking less feedback and engaging in less proactive behavior (Porath \& Bateman, 2006; VandeWalle \& Cummings, 1997). Such response patterns create team contexts where pertinent information for self-regulation (e.g., monitoring and evaluating progress toward task mastery) is scarce. Taken collectively, we expected the positive effects of LGO on self-regulation would be attenuated in teams with high mean levels of PPGO and APGO.

Hypothesis 5a: The positive effects of LGO on rates of change in individual-level self-regulation are attenuated in teams with high mean levels of PPGO.

Hypothesis $5 b$ : The positive effects of LGO on rates of change in individual-level self-regulation are attenuated in teams with high mean levels of APGO.

High PPGO individuals in team training can experience internalexternal referent dissimilarity if they are members of high mean LGO 
teams. In these contexts, high PPGO individuals would find themselves in teams where the comparative performance information they so desire is not collectively valued by the team. For example, high PPGO individuals tend to focus on task elements they perceive as most relevant to immediate performance (Elliot \& McGregor, 1999), but in high mean LGO teams emphasis would be placed on understanding all task elements presented for mastery (Harackiewicz, Barron, Tauer, Carter, \& Elliot, 2000). High PPGO individuals can also experience approach-avoidance dissimilarity when they are members of high mean APGO teams. Here, similar individual and team emphasis is placed on external comparisons of performance, but the incongruence stems from individual response patterns engaging such information and the team's context emphasizes disengagement. Both of these team contexts (high mean LGO or APGO) represent situations where more situationally relevant goals are not aligned with an individual's chronically active goals (DeShon \& Gillespie, 2005). Such situations are not only likely to frustrate high PPGO learners but also lead them to devote even more resources toward seeking external performance information at the further expense of allocating resources to task mastery (Seijts et al., 2004). We thus expected the negative effects of PPGO on self-regulation would be amplified in teams with high mean levels of LGO and APGO.

Hypothesis 6a: The negative effects of PPGO on rates of change in individual-level self-regulation are amplified in teams with high mean levels of LGO.

Hypothesis 6b: The negative effects of PPGO on rates of change in individual-level self-regulation are amplified in teams with high mean levels of APGO.

Finally, high APGO individuals can experience approach-avoidance dissimilarity when learning in teams characterized by high levels of approach tendencies (high mean LGO or PPGO teams). As discussed earlier, the negative effects of APGO on learning are generally thought to be associated with avoidance tendencies that are reflected in goal disengagement (Yeo et al., 2009), which can lead to a more disorganized and less persistent approach to learning. However, theory suggests that these detrimental effects could be buffered in certain contexts. For example, it is thought that approach tendencies could, at least to some extent, override avoidance tendencies (Elliot \& McGregor, 2001). Such a countervailing force is proffered to result from an individual's desire for discrepancy reduction (Carver \& Scheier, 1998), which is typified by approach-related tendencies. This suggests that team contexts characterized by approach tendencies among members could lessen the deleterious effects of high APGO. For instance, in teams of high mean LGO, 
positive approach-oriented cues for learning are likely to be more abundant as, on average, members are motivated to learn, engage in effective learning strategies, and display proactive behavior (Porter, 2008). High PPGO teams also provide increased approach-oriented cues, such as performance striving and affective task immersion (Elliot \& Harackiewicz, 1996). Although these team contexts activate or accentuate approachoriented goals, they are unlikely to completely negate individuals' chronically activated avoidance goals (DeShon \& Gillespie, 2005). Therefore, the negative effects of high APGO on individual-level self-regulation are likely lessened, but not fully overridden, in high mean LGO and PPGO teams.

Hypothesis 7a: The negative effects of APGO on rates of change in individual-level self-regulation are attenuated in teams with high mean levels of LGO.

Hypothesis $7 b$ : The negative effects of APGO on rates of change in individual-level self-regulation are attenuated in teams with high mean levels of PPGO.

\section{Linking Individual-Level Self-Regulation to Team-Level Outcomes}

In team training, a salient question is whether increases in selfregulation among team members translate to team-level learning. Certainly, variation in team outcomes is accounted for by more than individual-level factors (Hackman, 1987). Yet, because team members can interact with one another, the learning acquired by one member can transfer to his or her teammates and ultimately affect the team's collective learning process (Ellis et al., 2003). It is interesting to note that although there is substantial research examining learning processes at both the individual and team level, few efforts have focused on cross-level effects (Chen \& Klimoski, 2007). Because team competence is best conceptualized as multidimensional (Cannon-Bowers, Tannenbaum, Salas, Volpe, 1995; Ellis, Bell, Ployhart, Hollenbeck, \& Ilgen, 2005), we examined the effects of individual-level self-regulation within teams on three team-level outcomes. First, we measured the affective outcome of team efficacy, which represents a team's belief that it can successfully perform specific tasks (Lindsley, Brass, \& Thomas, 1995). Second, we examined a behavioral outcome reflecting the quality of cooperation in a team ("team-member exchange” [TMX]; Seers, 1989). Finally, team strategic decision-making effectiveness represented a team-level cognitive outcome.

There are several reasons to expect individual self-regulation to exert upward or bottom-up influences on these particular team-level 
outcomes. First, team members often develop similar beliefs because of shared cognitions, and these beliefs impact team processes and performance (Cannon-Bowers \& Salas, 2001). For example, the manner with which teams engage information processing shapes how effectively they perform, and metacognition is thought to be an important variable for understanding this processing (Hinsz, Tindale, \& Vollrath, 1997). Extending this line of reasoning, in addition to the team's strategy individuals must come to understand their own learning strategies (i.e., metacognition) during team training to promote team functioning and decision making. Increased self-reflection on one's learning within group contexts could also promote role-making processes by cuing members to think about how the role they play affects overall team performance. Role-making processes are thought to be central to team effectiveness because they enhance the quality of TMXs (Seers, Petty, \& Cashman, 1995).

Second, individuals' perceptions of their own capabilities can influence the efficacy perceptions of others in team contexts (Kozlowski, Gully, Salas, \& Cannon-Bowers, 1996), which in turn can shape beliefs about the team as a whole such as team efficacy (Gully, Incalcaterra, Joshi, \& Beaubein, 2002). One reason for this impact is because team training by nature entails learning with others and more socially rich settings can increase the prevalence of factors that enhance efficacy beliefs, such as opportunities for vicarious reinforcement and verbal persuasion (Bandura, 1982). Successful team performance during training also requires coordination of learning among team members. Such coordination should, in part, be affected by the extent to which individuals feel confident in their own capabilities to accomplish the tasks presented during team training. Training research supports the positive relationship between self-efficacy and learning (Colquitt, LePine, \& Noe, 2000). Thus, when a team's members are more self-efficacious they are more likely to engage in the tasks requisite to team training, and because these tasks are collective and require coordination, the effects of team member self-efficacy are likely to manifest in team-level performance.

Finally, at the team-level, efficacy-related beliefs (e.g., group potency) and team metacognition have been linked to effective team performance (Gully et al., 2002; Hinsz, 2004). Although theoretically distinct in terms of level and referent, such team-level findings suggest their individuallevel counterparts (self-efficacy and metacognition) could hold similar consequences for team-level learning outcomes. For the reasons discussed earlier, we expected that in teams where members engage in high levels of metacognition and possess high levels of self-efficacy during team training such increased self-regulation would lead to increased team-level 
outcomes. Put another way, when teams are composed of individuals that develop higher self-efficacy and engage in greater metacognitive activity, these teams will learn more effectively during team training. ${ }^{2}$

Hypothesis 8: Average self-efficacy among a team's members is positively related to team-level outcomes.

Hypothesis 9: Average metacognition among a team's members is positively related to team-level outcomes.

\section{Method}

\section{Participants and Training Setting}

Participants were undergraduate and graduate students enrolled in a capstone business course at a large midwestern university $(N=338)$. These participants were members of 64 teams, with four to six individuals on each team $(M=5.23)$. To reflect a realistic organizational context, teams had a multifunctional composition consisting of at least three different business majors or concentrations (e.g., accounting, marketing, management). Average age of the undergraduate participants was 22.9 years ( $56 \%$ male) and 31.5 years ( $72 \%$ male) for graduate participants.

A major focus of the course involved team training on both teamwork and taskwork components using multiple training techniques, including presentation and hands-on methods. Teamwork components included instructional topics such as critical team competencies, backing-up behavior, creating a team agenda, clarifying team roles, and the importance of coordination. Taskwork components included business strategy and strategic decision making in contemporary organizations. A primary training technique in the course was a team-based business simulation implemented using software developed by Capsim Business Simulations (www.capsim.com). The simulation requires participants to make complex sets of decisions working together as a team involving all aspects of a business's operation. The simulation has also been used in prior team research (e.g., Dierdorff, Bell, \& Belohlav, 2011; Mathieu \& Schulze, 2006).

Team performance on the simulation accounted for a significant portion of the participants' grades (24\% of total grade), thus ensuring sufficient effort and motivation. Teams competed in a real-time, interactive decision-making environment against other teams in the same course.

\footnotetext{
${ }^{2}$ Average self-efficacy and metacognition are compositional variables, not collective or team-level constructs. Thus, these additive team-level variables represent descriptive properties of teams and reflect the amounts of self-regulation among individual team members.
} 
The simulation software is designed to mimic a dynamic marketplace that reflects changing technology, customer values, and competition. Participant roles on their teams were similar to upper-level management in a manufacturing organization. Teams had to make decisions on a variety of issues such as research and development, marketing, production, human resources, total quality management, and finance. All teams began with equal resources and equal market positions and had to develop budgets and allocate finite resources based on competitive relationships. No teams were allowed to bankrupt and exit the simulation but instead were automatically given an emergency loan that included a penalty.

Prior to the simulation, participants were given a 36-page guide and access to an online tutorial and practice simulation. Teams made operating decisions twice weekly with the exception of the first two decisions that in the first week were to familiarize the participants with the simulation. Each decision cycle corresponded to a 1-year simulated timeframe, with teams performing for eight simulated fiscal years over a 5-week period. Following each decision point, teams received feedback from the simulation program regarding the effects of each decision in the form of reports that indexed the organization's performance. Goal orientation was assessed after the practice decisions. Self-efficacy and metacognition were collected after the second, fourth, and sixth team decisions, and a week prior to the eighth team decision. To ensure temporal precedence, team-level outcomes (team efficacy, quality of cooperation, and decision making) were assessed immediately after the third, fifth, seventh, and eighth decisions.

\section{Study Variables}

\section{Goal Orientation}

Trait goal orientation was assessed using VandeWalle's (1997) threefactor instrument. LGO was captured using five items, whereas PPGO and APGO were measured with four items each. Items were rated using a five-point scale $(1=$ strongly disagree to $5=$ strongly agree $)$. Sample items included "I often look for opportunities to develop new skills and knowledge" (LGO); "I try to figure out what it takes to prove my ability to others at work" (PPGO); and, "I prefer to avoid situations at work where I might perform poorly" (APGO). Similar to prior research on team goal orientation composition (LePine, 2005; Porter, 2005), we used an additive operationalization (Chan, 1998) where scores were averaged across all members of a team to produce team-level compositional variables, used in testing Hypotheses 4-7. 


\section{Task-Specific Self-Efficacy}

This variable was assessed with a six-item scale developed by the study's authors following the guidelines described by Bandura (1997). Instructions read, "when responding to the following items, think about your own thoughts, actions, and performance leading up to your most recent strategic decision for your Capstone company.” Items were rated on a five-point scale $(1=$ strongly disagree to $5=$ strongly agree $)$. Sample items read, "I am confident in my understanding of the interrelatedness of different business functions (R\&D, Production, Marketing, etc.)" and "I am confident in my understanding of how business strategy impacts business performance." Scores were also averaged across team members to create a team compositional variable for Hypotheses 8 and 9.

\section{Metacognition}

This variable was measured with a 10 -item scale derived from Schmidt and Ford (2003). Instructions and scale point anchors were the same as with self-efficacy. Sample items read, "I tried to determine which things I didn't understand well and adjusted my learning strategies accordingly," "I asked myself questions to make sure I understood the things I had been trying to learn," and "I thought about how well my tactics for learning were working." In addition, scores were averaged across team members to produce a team compositional variable for testing team-level predictions (Hypotheses 8 and 9).

\section{Team Efficacy}

This team-level affective learning outcome was measured using six items created by the study's authors following the guidelines and principles described by Bandura (1997) for developing self-efficacy scales. Items used the team as referent (i.e., referent-shift composition; Chan, 1998) and were rated using a five-point scale $(1=$ strongly disagree to $5=$ strongly agree). Instructions read, "when responding to the following items, think about the actions that happened within your team leading up to your most recent strategic decision for your Capstone company." Sample items read, "I am confident in my team's ability to collaboratively analyze and interpret business information regarding our organization" and "I am confident in my team's ability to develop effective strategy.” Evidence for aggregation was supportive for each time point, as levels of group-mean reliability (Intraclass correlation: ICC[2]) were all above 0.70 : Time 1 $\operatorname{ICC}(2)=0.70$; Time $2 \operatorname{ICC}(2)=0.76$; Time $3 \operatorname{ICC}(2)=0.72$; and Time $4 \operatorname{ICC}(2)=0.73$. 


\section{Team Cooperation Quality}

This team-level behavioral learning outcome was assessed using the 14-item TMX scale developed by Seers (1989) to capture the quality of reciprocal relationships among team members. Seers et al. (1995) note that aggregating team members' perceptions of reciprocity reflects the average reciprocity across the group. This reciprocity means that team members view both themselves and other team members as engaging in high-quality reciprocal cooperative behaviors (Dierdorff et al., 2011). Items were rated using a five-point scale $(1=$ strongly disagree to 5 $=$ strongly agree). Sample items included, "Other group members usually let me know what they expected from me," "I often made suggestions to other group members to improve performance," "When I was busy, other group members volunteered to help me out," and "I was willing to help finish work that had been given to other group members." Scores were averaged across team members to produce a teamlevel variable. Aggregation was supported with sufficient levels of groupmean reliability: Time $1 \operatorname{ICC}(2)=0.73$; Time $2 \operatorname{ICC}(2)=0.71$; Time 3 $\operatorname{ICC}(2)=0.72$; and, Time $4 \operatorname{ICC}(2)=0.76$.

\section{Team Strategic Decision Making}

This team-level cognitive learning outcome was operationalized using metrics generated by the simulation. These data correspond to financial indicators of business effectiveness typically used in real-world organizations: return-on-assets (ROA), return-on-sales (ROS), and stock value. The simulation computes these indicators by taking into account the decisions of each "company" relative to the simulated marketplace as a whole. Each of these measures views a company's level of performance relative to different aspects of its operation. ROA measures how effectively a company is using assets to reach its level of performance. ROS assesses a company's level of performance relative to the amount of generated sales. Stock value represents how effectively debt and equity are being used to create a firm's level of performance. These variables were standardized and a composite score was created. Coefficient alphas for the measure were $0.90,0.96,0.95$, and 0.89 across the four time points.

\section{Control Variables}

Participants were enrolled in either an undergraduate or a graduate version of the course, and thus, teams were homogenous in composition (i.e., all graduate students or all undergraduate students). We controlled for this difference using a dichotomously coded variable 
$(0=$ undergraduate, $1=$ graduate $)$. In testing team-level hypotheses (8 and 9), we used average levels of self-efficacy and metacognition to describe these learning outcomes within a team. Team composition variables operationalized as the team mean have shown consistently stronger relationships with team outcomes than when operationalized as other descriptive properties such as variability (Bell, 2007). However, to allow for a more comprehensive examination of the relationships between self-efficacy, metacognition, and team-level learning outcomes, we also included the level of variability within the team as a potential covariate.

\section{Analytical Strategy}

Hypotheses 1-7 were tested using multilevel growth modeling to simultaneously analyze intraindividual change in self-efficacy and metacognition, interindividual differences in growth trajectories and posttraining status on each outcome, and interteam moderators of the individuallevel predictors of growth. Analyses were conducted using HLM 6 (Raudenbush, Bryk, Cheong, \& Congdon, 2004) and followed a staged approach (Raudenbush \& Bryk, 2002). First, three-level unconditional growth models were conducted to test for significant differences between individuals (Level 2) and teams (Level 3) in growth trajectories (slopes). Second, for Hypotheses 1-3 conditional growth models were used to test the individual-level (Level-2) predictors of growth trajectories (slopes). Third, team goal orientation compositions were entered as Level3 moderators of the individual-level predictors of growth, as posited by Hypotheses 4-7.3

For Hypotheses 8 and 9, separate multilevel growth models tested intrateam change and interteam differences in team-level outcomes. We first estimated a two-level unconditional growth model to test for significant differences between teams in posttraining team-level outcomes and in growth trajectories of these outcomes. Next, team averages on

\footnotetext{
${ }^{3}$ Hypotheses 4-7 predicted cross-level interactions between team goal orientation composition and individual-level goal orientation with respect individual-level self-regulation over time (i.e., slopes). Results from models including only the three-way interaction terms directly test these predictions. Raudenbush and Bryk (2002) recommend that prior to testing such models one should examine if higher level variables (team mean goal orientation) display main effects or lower order interactions. We tested this possibility using models that posited main effects of team mean goal orientation on individual-level self-efficacy and metacognition (i.e., intercepts), in addition to all possible two-way interactions (i.e., other random slopes). Only one parameter was significant, the main effect of team mean PPGO on self-efficacy, $p<0.05$ ). Including this parameter in the model testing our predicted cross-level effects did not change the significance of any cross-level parameters. We thus present only results from the more parsimonious models testing our hypotheses.
} 
self-efficacy and metacognition at each time point were entered into the model as "time-varying covariates," which is appropriate when both the predictors and criterion vary over time (Raudenbush \& Bryk, 2002). Timevarying covariates were group-mean centered to avoid bias that occurs when the aggregate of a covariate has a separate but distinct relationship with the intercept (Raudenbush \& Bryk, 2002). This model's results indicate longitudinal relationships between team-level outcomes and team averages on self-efficacy and metacognition. Team-level outcomes were measured after self-efficacy and metacognition, ensuring temporal precedence.

\section{Results}

Tables 2 and 3 present descriptive statistics, zero-order correlations, and scale reliabilities for study variables. Bivariate individual-level correlations are shown in Table 2. LGO displayed significant positive correlations, and APGO significant negative correlations $(p<0.01)$, with individuals' levels of self-efficacy and metacognition across all time points. The bivariate correlations showed PPGO was largely unrelated to individual-level learning outcomes. Across the four assessments, selfefficacy and metacognition were positively related $(S D<0.01)$.

The bivariate correlations for team-level variables are shown in Table 3. Of the possible relationships, $54 \%$ of the correlations between average levels of self-efficacy within teams and the three team-level outcomes were positive and significant $(S D<0.05$, mean $r=0.28$ ). As for average levels of metacognition, $58 \%$ of the possible correlations with the three team-level outcomes were significant $(S D<0.05$, mean $r=$ 0.27). Finally, affective, behavioral, and cognitive team-level outcomes were positively and significantly related across time points (mean $r=$ $0.43)$.

Results from the unconditional growth model for self-efficacy showed a significant positive average linear growth parameter $\left(\gamma_{000}=0.091\right.$, $S D<0.01$ ), significant variance among individuals within teams in posttraining status $\left(T_{\Pi_{0}}=0.248, d f=271, X^{2}=1165.287, S D<0.01\right)$ and growth trajectories $\left(T_{\Pi_{1}}=0.018, d f=271, X^{2}=503.288, S D<\right.$ $0.01)$, and significant variation between teams in mean posttraining status $\left(T_{\beta 00}=0.022, d f=57, X^{2}=80.315, S D<0.05\right)$ and mean growth trajectories $\left(T_{\beta 10}=0.002, d f=57, X^{2}=77.918, S D<\right.$ 0.05 ). Results also indicated that $66 \%$ of the variability in selfefficacy resided between individuals and 6\% between teams, after accounting for individual growth. Unconditional growth model results for metacognition indicated significant positive average linear growth $\left(\gamma_{000}=0.089, S D<0.01\right)$, significant variance among individuals 
TABLE 2

Descriptive Statistics and Zero-Order Correlations for all Individual-Level Variables

\begin{tabular}{|c|c|c|c|c|c|c|c|c|c|c|c|c|c|c|}
\hline $\begin{array}{l}\text { Individual-level } \\
\text { variables }\end{array}$ & $M$ & $S D$ & 1 & 2 & 3 & 4 & 5 & 6 & 7 & 8 & 9 & 10 & 11 & 12 \\
\hline 1. Education level & 0.30 & 0.46 & . & & & & & & & & & & & \\
\hline 2. LGO & 4.18 & 0.60 & 0.27 & 0.85 & & & & & & & & & & \\
\hline 3. PPGO & 3.41 & 0.77 & 0.02 & 0.15 & 0.81 & & & & & & & & & \\
\hline 4. APGO & 2.57 & 0.83 & -0.18 & -0.38 & 0.27 & 0.83 & & & & & & & & \\
\hline 5. Self-efficacy (T1) & 3.93 & 0.53 & 0.02 & 0.27 & 0.01 & -0.23 & 0.83 & & & & & & & \\
\hline 6. Self-efficacy (T2) & 3.99 & 0.58 & 0.07 & 0.23 & -0.03 & -0.29 & 0.64 & 0.86 & & & & & & \\
\hline 7. Self-efficacy (T3) & 4.10 & 0.58 & 0.13 & 0.32 & -0.04 & -0.24 & 0.48 & 0.63 & 0.89 & & & & & \\
\hline 8. Self-efficacy (T4) & 4.18 & 0.58 & 0.18 & 0.40 & -0.01 & -0.28 & 0.44 & 0.55 & 0.72 & 0.92 & & & & \\
\hline 9. Metacognition (T1) & 3.88 & 0.51 & -0.10 & 0.25 & 0.12 & -0.16 & 0.46 & 0.37 & 0.32 & 0.29 & 0.84 & & & \\
\hline 10. Metacognition (T2) & 3.96 & 0.51 & -0.02 & 0.30 & 0.01 & -0.23 & 0.44 & 0.51 & 0.42 & 0.35 & 0.74 & 0.87 & & \\
\hline 11. Metacognition (T3) & 4.06 & 0.50 & 0.04 & 0.35 & -0.04 & -0.22 & 0.35 & 0.41 & 0.59 & 0.51 & 0.58 & 0.69 & 0.90 & \\
\hline 12. Metacognition (T4) & 4.15 & 0.54 & 0.10 & 0.45 & -0.14 & -0.24 & 0.32 & 0.41 & 0.56 & 0.69 & 0.48 & 0.58 & 0.74 & 0.90 \\
\hline
\end{tabular}

Note. $N=338$ for individual-level variables; Coefficient alphas shown on diagonal in bold; Correlations greater than $0.11, p<0.05$; Correlations greater than $0.15, p<0.01$. 
TABLE 3

Descriptive Statistics and Zero-Order Correlations for Team-Level Variables

\begin{tabular}{|c|c|c|c|c|c|c|c|c|c|c|c|c|c|c|c|c|c|c|c|c|c|c|c|c|}
\hline Team-level variables & $M$ & SD & 1 & 2 & 3 & 4 & 5 & 6 & 7 & 8 & 9 & 10 & 11 & 12 & 13 & 14 & 15 & 16 & 17 & 18 & 19 & 20 & 21 & 22 \\
\hline 1. Avg LGO & 4.21 & 0.27 & & & & & & & & & & & & & & & & & & & & & & \\
\hline 2. Avg PPGO & 3.41 & 0.34 & 0.23 & & & & & & & & & & & & & & & & & & & & & \\
\hline 3. Avg APGO & 2.53 & 0.39 & -0.48 & 0.26 & & & & & & & & & & & & & & & & & & & & \\
\hline 4. Avg self-efficacy (T1) & 3.90 & 0.31 & 0.19 & 0.16 & -0.14 & & & & & & & & & & & & & & & & & & & \\
\hline 5. Avg self-efficacy (T2) & 3.95 & 0.37 & 0.22 & 0.17 & -0.17 & 0.67 & & & & & & & & & & & & & & & & & & \\
\hline 6. Avg self-efficacy (T3) & 4.06 & 0.33 & 0.26 & -0.03 & -0.28 & 0.51 & 0.77 & & & & & & & & & & & & & & & & & \\
\hline 7. Avg self-efficacy (T4) & 4.16 & 0.34 & 0.31 & -0.01 & -0.32 & 0.49 & 0.72 & 0.76 & & & & & & & & & & & & & & & & \\
\hline 8. Avg metacognition (T1) & 3.88 & 0.23 & 0.15 & 0.29 & -0.09 & 0.56 & 0.21 & 0.09 & 0.07 & & & & & & & & & & & & & & & \\
\hline 9. Avg metacognition (T2) & 3.94 & 0.26 & 0.21 & 0.22 & 0.03 & 0.48 & 0.48 & 0.38 & 0.43 & 0.53 & & & & & & & & & & & & & & \\
\hline 10. Avg metacognition (T3) & 4.05 & 0.23 & 0.41 & 0.25 & -0.02 & 0.42 & 0.51 & 0.62 & 0.56 & 0.29 & 0.67 & & & & & & & & & & & & & \\
\hline 11. Avg metacognition (T4) & 4.17 & 0.25 & 0.41 & 0.15 & -0.19 & 0.26 & 0.27 & 0.40 & 0.66 & 0.19 & 0.40 & 0.65 & & & & & & & & & & & & \\
\hline 12. Team efficacy (T1) & 4.04 & 0.41 & 0.16 & 0.15 & -0.06 & 0.31 & 0.16 & 0.02 & 0.21 & 0.27 & 0.21 & 0.08 & 0.20 & & & & & & & & & & & \\
\hline 13. Team efficacy (T2) & 4.01 & 0.41 & 0.25 & 0.15 & -0.23 & 0.27 & 0.41 & 0.33 & 0.51 & 0.05 & 0.21 & 0.20 & 0.33 & 0.67 & & & & & & & & & & \\
\hline 14. Team efficacy (T3) & 4.10 & 0.39 & 0.11 & 0.02 & -0.17 & 0.11 & 0.35 & 0.51 & 0.55 & 0.03 & 0.20 & 0.37 & 0.39 & 0.53 & 0.70 & & & & & & & & & \\
\hline 15. Team efficacy (T4) & 4.19 & 0.41 & 0.16 & 0.07 & -0.24 & 0.17 & 0.40 & 0.40 & 0.56 & 0.13 & 0.19 & 0.32 & 0.42 & 0.56 & 0.67 & 0.88 & & & & & & & & \\
\hline 16. TMX (T1) & 3.83 & 0.32 & 0.37 & 0.11 & -0.14 & 0.17 & 0.13 & 0.07 & 0.24 & 0.13 & 0.33 & 0.42 & 0.38 & 0.39 & 0.15 & 0.32 & 0.32 & & & & & & & \\
\hline 17. TMX (T2) & 3.87 & 0.31 & 0.20 & 0.12 & 0.09 & 0.16 & 0.13 & 0.10 & 0.19 & 0.09 & 0.34 & 0.37 & 0.31 & 0.42 & 0.39 & 0.36 & 0.28 & 0.55 & & & & & & \\
\hline 18. TMX (T3) & 3.98 & 0.30 & 0.21 & 0.01 & -0.02 & -0.04 & 0.07 & 0.20 & 0.28 & -0.10 & 0.24 & 0.42 & 0.37 & 0.35 & 0.37 & 0.51 & 0.38 & 0.50 & 0.86 & & & & & \\
\hline 19. TMX (T4) & 4.07 & .28 & 0.40 & 0.01 & -0.31 & 0.22 & 0.41 & 0.52 & 0.69 & 0.08 & 0.33 & 0.60 & 0.67 & 0.39 & 0.51 & 0.70 & 0.71 & 0.48 & 0.57 & 0.69 & & & & \\
\hline 20. Team decisions (T1) & 14.38 & 7.74 & 0.11 & 0.14 & 0.09 & 0.22 & 0.22 & 0.08 & 0.22 & 0.17 & 0.24 & 0.13 & 0.18 & 0.46 & 0.51 & 0.34 & 0.38 & 0.08 & 0.14 & 0.02 & 0.07 & & & \\
\hline 21. Team decisions (T2) & 17.25 & 12.68 & 0.33 & 0.20 & -0.05 & 0.23 & 0.41 & 0.31 & 0.39 & 0.09 & 0.40 & 0.36 & 0.32 & 0.29 & 0.51 & 0.51 & 0.51 & 0.27 & 0.18 & 0.15 & 0.32 & 0.66 & & \\
\hline 22. Team decisions (T3) & 27.79 & 18.04 & 0.27 & 0.16 & -0.04 & 0.22 & 0.37 & 0.39 & 0.43 & 0.08 & 0.31 & 0.48 & 0.43 & 0.33 & 0.49 & 0.57 & 0.61 & 0.30 & 0.26 & 0.25 & 0.40 & 0.63 & 0.67 & \\
\hline 23. Team decisions (T4) & 51.87 & 24.27 & 0.16 & 0.08 & -0.02 & 0.17 & 0.30 & 0.28 & 0.44 & -0.04 & 0.27 & 0.37 & 0.40 & 0.31 & 0.38 & 0.45 & 0.49 & 0.31 & 0.12 & 0.14 & 0.26 & 0.65 & 0.63 & 0.84 \\
\hline
\end{tabular}

Note. $N=64$ for team-level variables; Avg = average; TMX = team-member-exchange (team cooperation quality); team decisions = team strategic decision making; Correlations greater than $0.25 S D<0.05$; correlations greater than $0.32 S D<0.01$. 
within teams in posttraining status $\left(T_{\Pi 0}=0.234, d f=271\right.$, $\left.X^{2}=1572.913, S D<0.01\right)$ and growth trajectories $\left(T_{\Pi 1}=0.020, d f=\right.$ 271, $\left.X^{2}=653.618, S D<0.01\right)$, significant variation between teams in mean growth trajectories $\left(T_{\beta 10}=0.002, d f=57, X^{2}=79.476, S D\right.$ $<0.05$ ), but nonsignificant between-team variance in mean posttraining status $\left(T_{\beta 00}=0.003, d f=57, X^{2}=63.518\right)$. After accounting for growth, $77 \%$ of the variability in metacognition resided between individuals, and $1 \%$ resided between teams. Finally, we also tested for nonlinear rates of change (quadratic trends). The quadratic growth parameters for self-efficacy and metacognition were not statistically significant $(S D>0.50)$ and indicated that linear change adequately represented the data.

The two-level unconditional growth model for team-level outcomes indicated significant $(p<0.01)$ between-team variance in all three outcomes at the end of training, as well as growth trajectories during training: posttraining team efficacy $\left(T_{00}=0.137, d f=63, X^{2}=316.623\right)$ and team efficacy growth trajectories $\left(T_{01}=0.011, d f=63, X^{2}=133.660\right)$; posttraining cooperation quality $\left(T_{00}=0.072, d f=63, X^{2}=224.039\right)$ and cooperation quality growth trajectories $\left(T_{01}=0.004, d f=63, X^{2}=\right.$ 94.679); and, posttraining decision-making effectiveness ( $T_{00}=474.839$, $\left.d f=63, X^{2}=507.807\right)$ and decision-making growth trajectories $\left(T_{01}=\right.$ 33.588, $\left.d f=63, X^{2}=155.903\right)$.

\section{Conditional Growth Models for Hypothesis Testing}

Hypothesis 1-3 pertained to the effects of dispositional goal orientation on changes in self-regulation. Results for these hypotheses are provided in Table 4. Hypothesis 1 predicted positive effects of LGO on change in individual-level self-regulation. This hypothesis was fully supported as LGO was positively related to rates of change in both self-efficacy and metacognition $\left(\gamma_{110}=0.047, p<0.05\right.$, and 0.062, $p<0.01$, respectively). Hypothesis 2 predicted PPGO to be negatively related to rates of self-regulation. This hypothesis also received full support with PPGO showing negative effects on changes in self-efficacy and metacognition $\left(\gamma_{120}=-0.028\right.$ and $-0.019, p<0.05$, respectively). Finally, Hypothesis 3 predicted APGO to be negatively related to rates of self-regulation. This hypothesis received partial support with higher levels of APGO associated with lower rates of metacognition $\left(Y_{130}=-0.027, p<0.05\right)$ but not self-efficacy. Dispositional goal orientation explained $43 \%$ of the betweenindividual variance in posttraining self-efficacy and $57 \%$ of the betweenindividual variance in rates of change. With regard to metacognition, dispositional goal orientation explained 39\% of the between-individual 
TABLE 4

Conditional Growth Model Results for Individual-Level Effects on Self-Efficacy and Metacognition

\begin{tabular}{|c|c|c|c|c|c|c|}
\hline \multirow[b]{2}{*}{ Fixed effects } & \multicolumn{3}{|c|}{ Self-efficacy } & \multicolumn{3}{|c|}{ Metacognition } \\
\hline & Coefficient & $S E$ & $t$-ratio & Coefficient & $S E$ & $t$-ratio \\
\hline \multicolumn{7}{|c|}{ Main effects on posttraining status } \\
\hline Intercept, $Y_{000}$ & $4.152 * *$ & 0.042 & 99.075 & $4.164^{* *}$ & 0.033 & 126.923 \\
\hline $\mathrm{LGO}, \gamma_{010}$ & $0.367^{* *}$ & 0.069 & 5.300 & $0.363^{* *}$ & 0.054 & 6.734 \\
\hline PPGO, $\gamma_{020}$ & -0.042 & 0.043 & -0.974 & -0.029 & 0.040 & -0.731 \\
\hline APGO, $\gamma_{030}$ & $-0.084^{* *}$ & 0.042 & -2.018 & $-0.062^{*}$ & 0.033 & -1.894 \\
\hline Education level, $Y_{040}$ & 0.075 & 0.066 & 1.144 & -0.063 & 0.054 & -1.173 \\
\hline \multicolumn{7}{|l|}{ Cross-level growth moderation } \\
\hline Intercept, $Y_{100}$ & $0.072 * *$ & 0.013 & 5.458 & $0.076^{* *}$ & 0.012 & 6.459 \\
\hline LGO $\times$ growth, $\gamma_{110}$ & $0.047^{*}$ & 0.026 & 1.817 & $0.062 * *$ & 0.022 & 2.860 \\
\hline PPGO $\times$ growth, $Y_{120}$ & $-0.028^{*}$ & 0.017 & -1.672 & $-0.019^{*}$ & 0.011 & -1.667 \\
\hline APGO $\times$ growth, $Y 130$ & -0.008 & 0.013 & -0.604 & $-0.027^{*}$ & 0.014 & -1.954 \\
\hline $\begin{array}{l}\text { Education level } \times \text { growth, } \\
\quad Y_{140}\end{array}$ & $0.052^{* *}$ & 0.020 & 2.594 & $0.046^{* *}$ & 0.018 & 2.520 \\
\hline
\end{tabular}

Note. $S E$ = robust standard error; LGO = learning goal orientation, PPGO = prove performance goal orientation, APGO $=$ avoid performance goal orientation. ${ }^{*} p \leq 0.05,{ }^{* *} p \leq$ 0.01 (one-tailed).

variance in posttraining metacognition and $41 \%$ of the between-individual variance in growth rates. ${ }^{4}$

Table 5 presents the conditional growth model results for the teamlevel (Level-3) moderating effects of team goal orientation compositions on individual-level self-regulation. Hypotheses $4 \mathrm{a}$, b, and c predicted that the effects of individual-level goal orientation (positive for LGO, negative for PPGO and APGO) are amplified in teams with high mean levels of the parallel orientations (i.e., three-way interactions). Results showed crosslevel moderation for team mean LGO on changes in metacognition $\left(Y_{111}\right.$ $=-0.166, p<0.01$ ) but not self-efficacy. The form of this interaction is shown in Figure 1 (top plot) and indicates that the effects of individuallevel LGO on changes in metacognition are amplified in high mean LGO teams (e.g., steepest trajectory for high LGO individuals in high mean LGO teams). This finding provides partial support for Hypothesis 4a. Results showed significant cross-level moderation for team mean PPGO on growth in self-efficacy only $\left(Y_{122}=-0.092, p<0.01\right)$ and the form of this interaction (Figure 1, middle plot) was as predicted with high team mean PPGO amplifying the negative effects of individual-level PPGO

\footnotetext{
${ }^{4}$ Some research (e.g., Bouffard et al., 1995; Button et al., 1996; Pintrich, 2000) suggests potential effects for within-individual goal orientation profiles (e.g., LGO $\times$ PPGO). Although our emphasis is on cross-level effects, we examined the possibility of withinlevel interactions at the individual-level in our data. Of the six possible individual-level interactions, a significant effect $(p<0.05)$ was found for only one interaction (LGO $\times$ PPGO predicting changes in metacognition).
} 
TABLE 5

Conditional Growth Model Results for Team-Level Moderation on Self-Efficacy and Metacognition

\begin{tabular}{|c|c|c|c|c|c|c|}
\hline \multirow[b]{2}{*}{ Fixed effects } & \multicolumn{3}{|c|}{ Self-efficacy } & \multicolumn{3}{|c|}{ Metacognition } \\
\hline & Coefficient & $S E$ & $t$-ratio & Coefficient & $S E$ & $t$-ratio \\
\hline $\begin{array}{l}\text { Team mean LGO } \times \text { LGO } \times \\
\text { Growth, } Y_{111}\end{array}$ & -0.083 & 0.100 & -0.835 & $-0.166^{* *}$ & 0.068 & -2.426 \\
\hline $\begin{array}{l}\text { Team mean PPGO } \times \text { LGO } \times \\
\text { Growth, } y_{112}\end{array}$ & -0.031 & 0.049 & -0.633 & 0.004 & 0.040 & 0.098 \\
\hline $\begin{array}{l}\text { Team mean APGO } \times \text { LGO } \times \\
\text { Growth, } Y_{113}\end{array}$ & $-0.125^{* *}$ & 0.057 & -2.171 & $-0.126^{* *}$ & 0.042 & -3.009 \\
\hline $\begin{array}{l}\text { Team mean LGO } \times \text { PPGO } \times \\
\text { Growth, } Y_{121}\end{array}$ & $0.135^{* *}$ & 0.064 & 2.105 & -0.005 & 0.063 & -0.080 \\
\hline $\begin{array}{l}\text { Team mean PPGO } \times \text { PPGO } \times \\
\text { Growth, } Y_{122}\end{array}$ & $-0.092^{* *}$ & 0.029 & -3.157 & -0.015 & 0.027 & -0.576 \\
\hline $\begin{array}{l}\text { Team mean APGO } \times \text { PPGO } \times \\
\text { Growth, } Y_{123}\end{array}$ & 0.019 & 0.034 & 0.560 & $0.071^{* *}$ & 0.035 & 2.056 \\
\hline $\begin{array}{l}\text { Team mean LGO } \times \text { APGO } \times \\
\text { Growth, } \gamma_{131}\end{array}$ & -0.024 & 0.051 & -0.481 & $0.099 * *$ & 0.038 & 2.633 \\
\hline $\begin{array}{l}\text { Team mean PPGO } \times \text { APGO } \times \\
\text { Growth, } Y_{132}\end{array}$ & -0.008 & 0.037 & -0.211 & $-0.075^{* *}$ & 0.031 & -2.398 \\
\hline $\begin{array}{l}\text { Team mean APGO } \times \text { APGO } \times \\
\text { Growth, } Y_{133}\end{array}$ & 0.032 & 0.031 & 1.038 & $0.088^{* *}$ & 0.027 & 3.299 \\
\hline
\end{tabular}

Note. For purposes of brevity, only cross-level moderation parameters are shown; $S E=$ robust standard error; LGO = learning goal orientation; PPGO = prove performance goal orientation; APGO = avoid performance goal orientation.

${ }^{*} p \leq 0.05,{ }^{* *} p \leq 0.01$ (one-tailed).

(i.e., flattening the trajectory). Team mean PPGO did not moderate metacognition and thus, Hypothesis 4b was partially supported. Finally, results indicated cross-level moderation for team mean APGO on growth in metacognition $\left(Y_{111}=0.088, p<0.01\right)$ but not self-efficacy. This moderation was as predicted with greater negative effects in high mean APGO teams (Figure 1, bottom plot) and provides partial support for Hypothesis 4c.

Hypotheses 5-7 related to predictions regarding dissimilarity between individual-level goal orientation and team goal orientation compositions. ${ }^{5}$

\footnotetext{
${ }^{5}$ Although the variability in team size was small in our study (four to six members), we tested for potential effects of team size in our data. Two sets of analyses were conducted. First, team size was entered as team-level predictor of the individual-level goal orientation effects on changes in metacognition and self-efficacy. No significant effects were found $(p>$ 0.10 for all parameters). Second, team size was entered as an additional team-level predictor in the models used to test Hypotheses 4-7 (Table 5 results). Of the six potential effects, team size showed only one significant effect in these models. For changes in metacognition, the team size $\times$ APGO $\times$ growth parameter was significant $\left(Y_{\text {iii }}=0.023, p<0.05\right)$. The inclusion of team size did not change the significance or sign of any parameters pertinent to our hypotheses.
} 

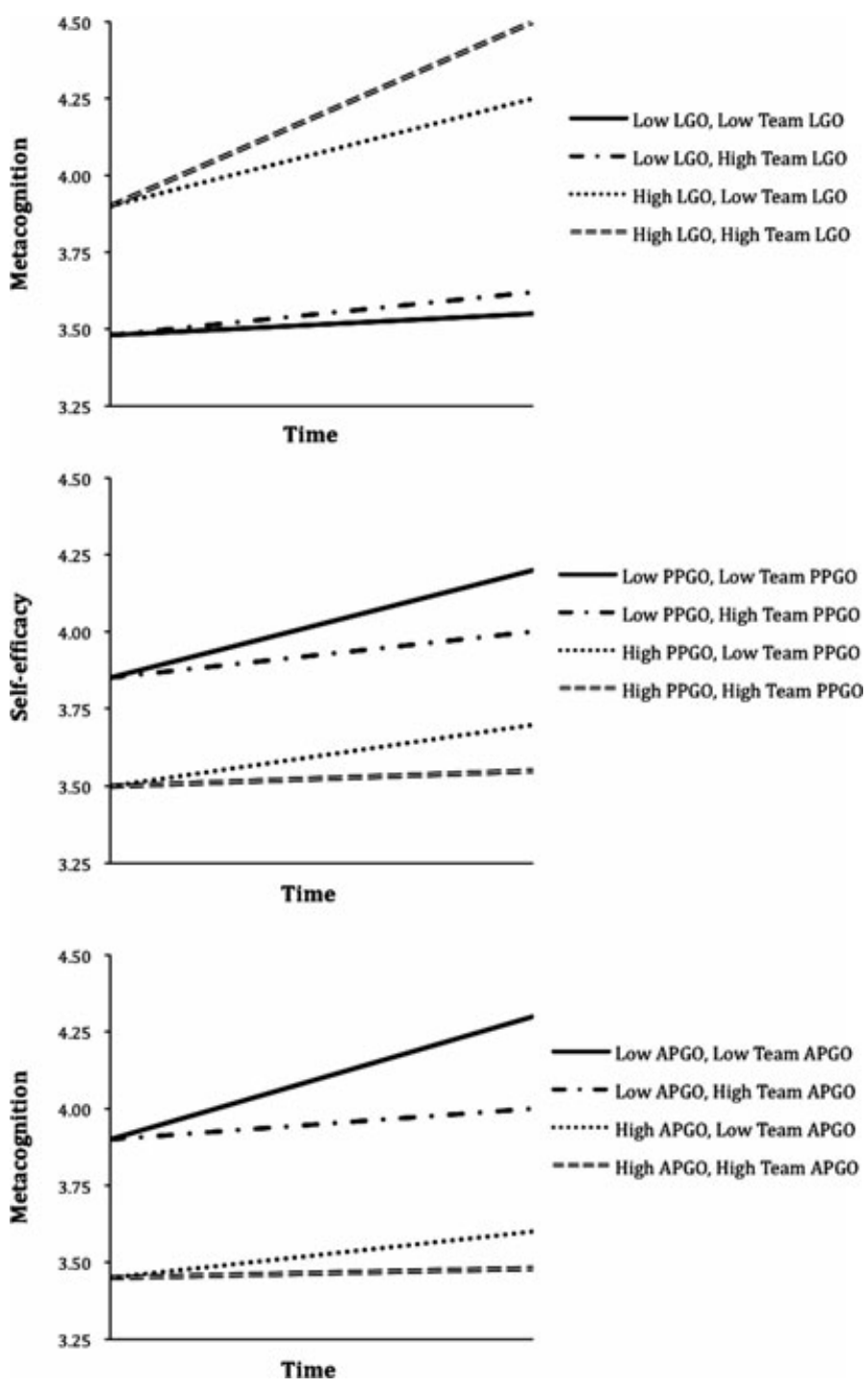

Figure 1: Cross-Level Moderation by Parallel Team Goal Orientation Compositions.

Hypotheses $5 \mathrm{a}$ and $\mathrm{b}$ predicted that the positive effects of individuallevel LGO are attenuated in teams with high mean levels of PPGO and APGO. Team mean PPGO did not display significant cross-level moderation, failing to support Hypothesis 5a. Results showed team mean APGO significantly moderated growth in both self-efficacy $\left(\gamma_{113}=-0.125\right.$, 

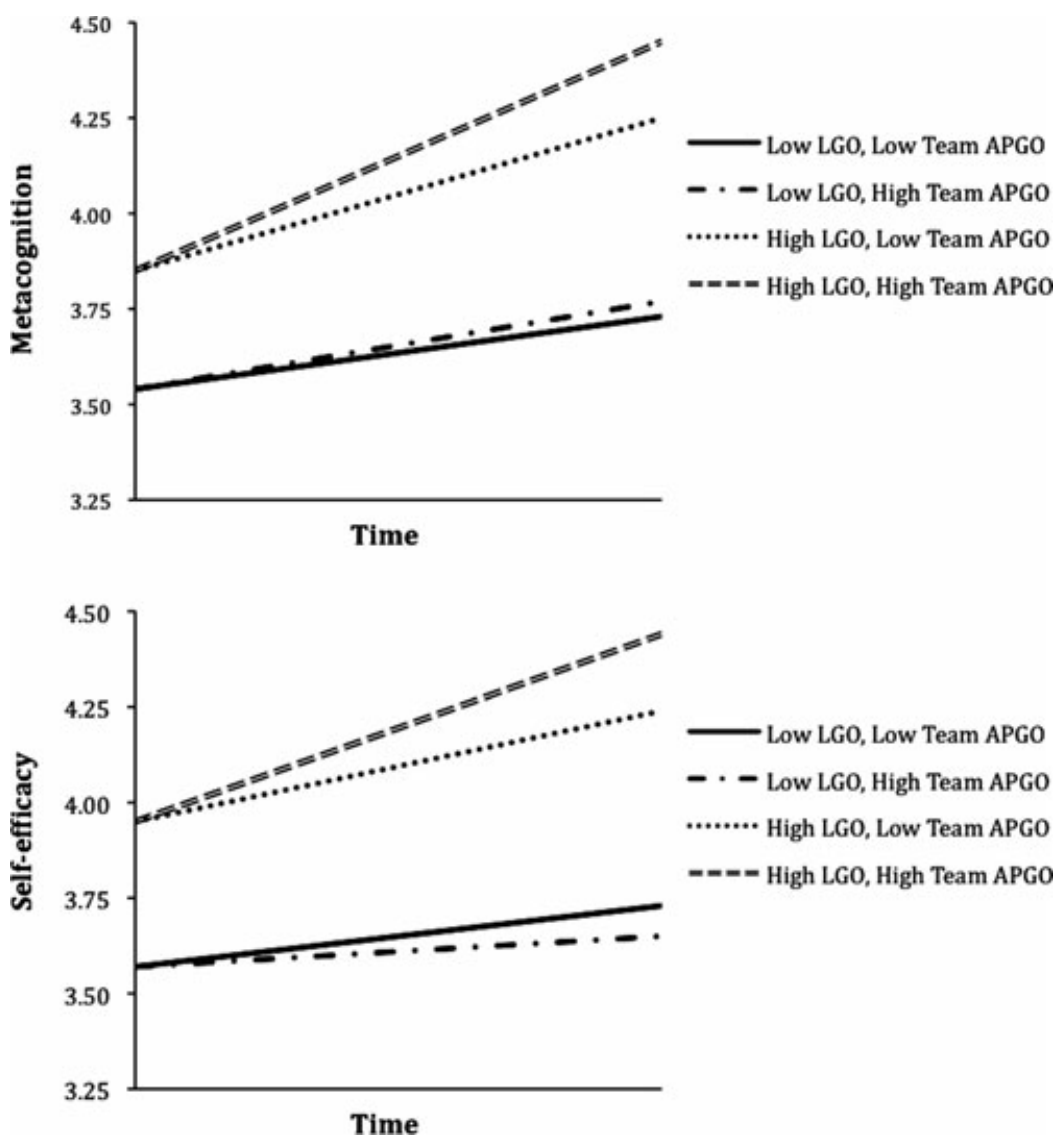

Figure 2: Cross-Level Moderation of LGO by Dissimilar Team Goal Orientation Compositions.

$p<0.01)$ and metacognition $\left(\gamma_{113}=-0.126, p<0.01\right)$. However, these interactions (see Figure 2) were not in the predicted forms of attenuation but rather amplification and thus failed to support Hypothesis $5 b$.

Hypotheses $6 \mathrm{a}$ and $\mathrm{b}$ predicted that the negative effects of individuallevel PPGO are amplified for teams with high mean levels of LGO and APGO. Team mean LGO moderated the effects of individual-level PPGO and growth in self-efficacy $\left(\gamma_{121}=0.135, p<0.01\right)$ but not metacognition. Figure 3 (top plot) shows that team mean LGO increased the negative effects of PPGO (i.e., flatter trajectory), offering partial support for Hypothesis 6a. Team mean APGO moderated the effects of individual-level PPGO on growth in metacognition $\left(\gamma_{123}=0.071\right.$, $p<0.01$ ) but not self-efficacy. As shown in Figure 3 (bottom plot), high 

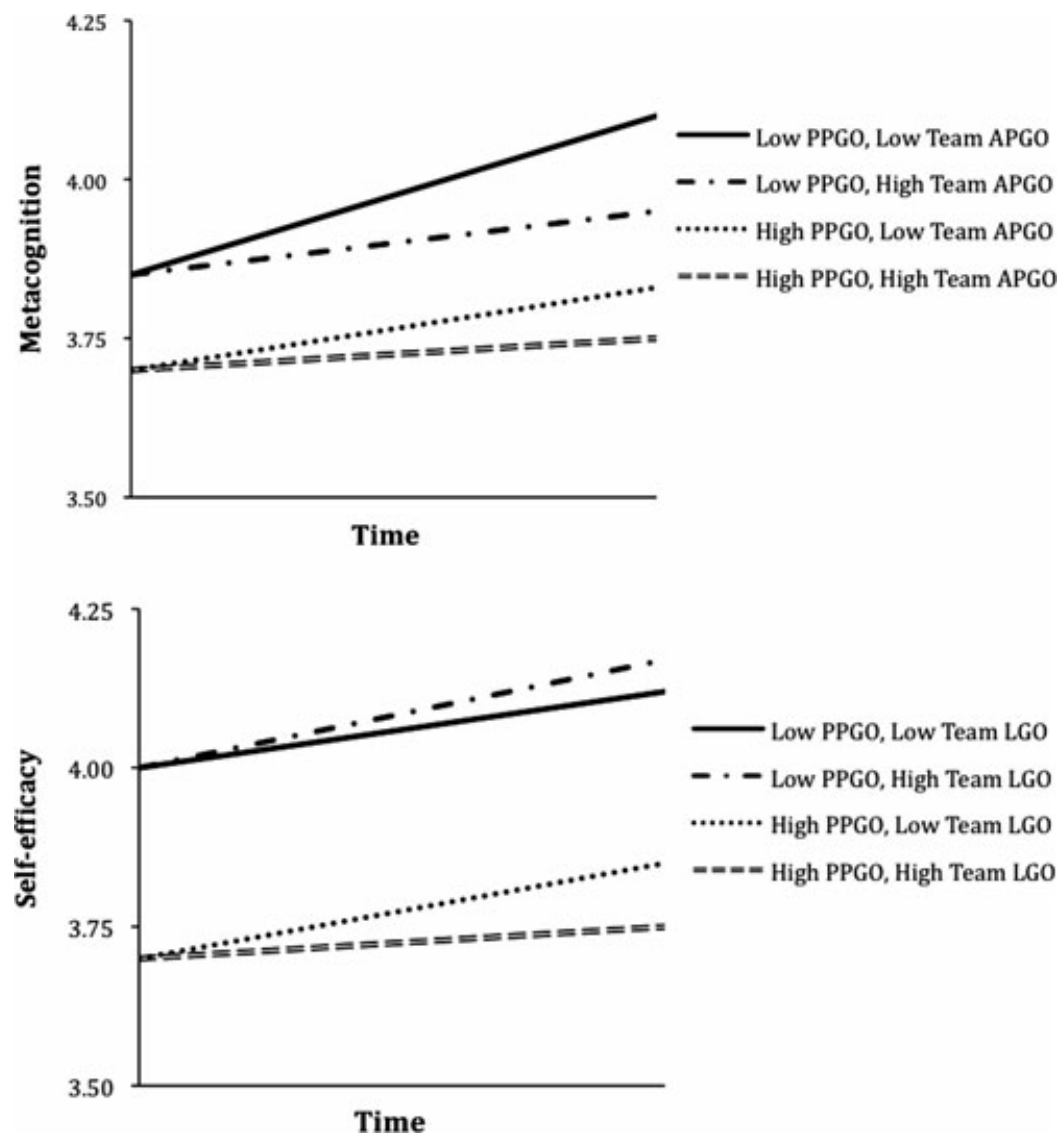

Figure 3: Cross-Level Moderation of PPGO by Dissimilar Team Goal Orientation Compositions.

team mean APGO accentuated the negative effects of PPGO, partially supporting Hypothesis $6 \mathrm{~b}$.

Hypotheses $7 \mathrm{a}$ and $\mathrm{b}$ predicted that the negative effects of individuallevel APGO are attenuated in teams with high mean levels of LGO and PPGO. Team mean LGO moderated the effects of individual-level APGO on changes in metacognition only $\left(Y_{131}=0.099, p<0.01\right)$. As shown in Figure 4 (top plot), high team mean LGO lessened the negative effects of high APGO (i.e., steeper trajectory), which partially supports Hypothesis 7a. Similarly, team mean PPGO moderated the effects of individual-level APGO on growth in metacognition $\left(\gamma_{132}=-0.075\right.$, $p<0.01$ ) but not self-efficacy. Partially supporting Hypothesis $7 \mathrm{~b}$, 

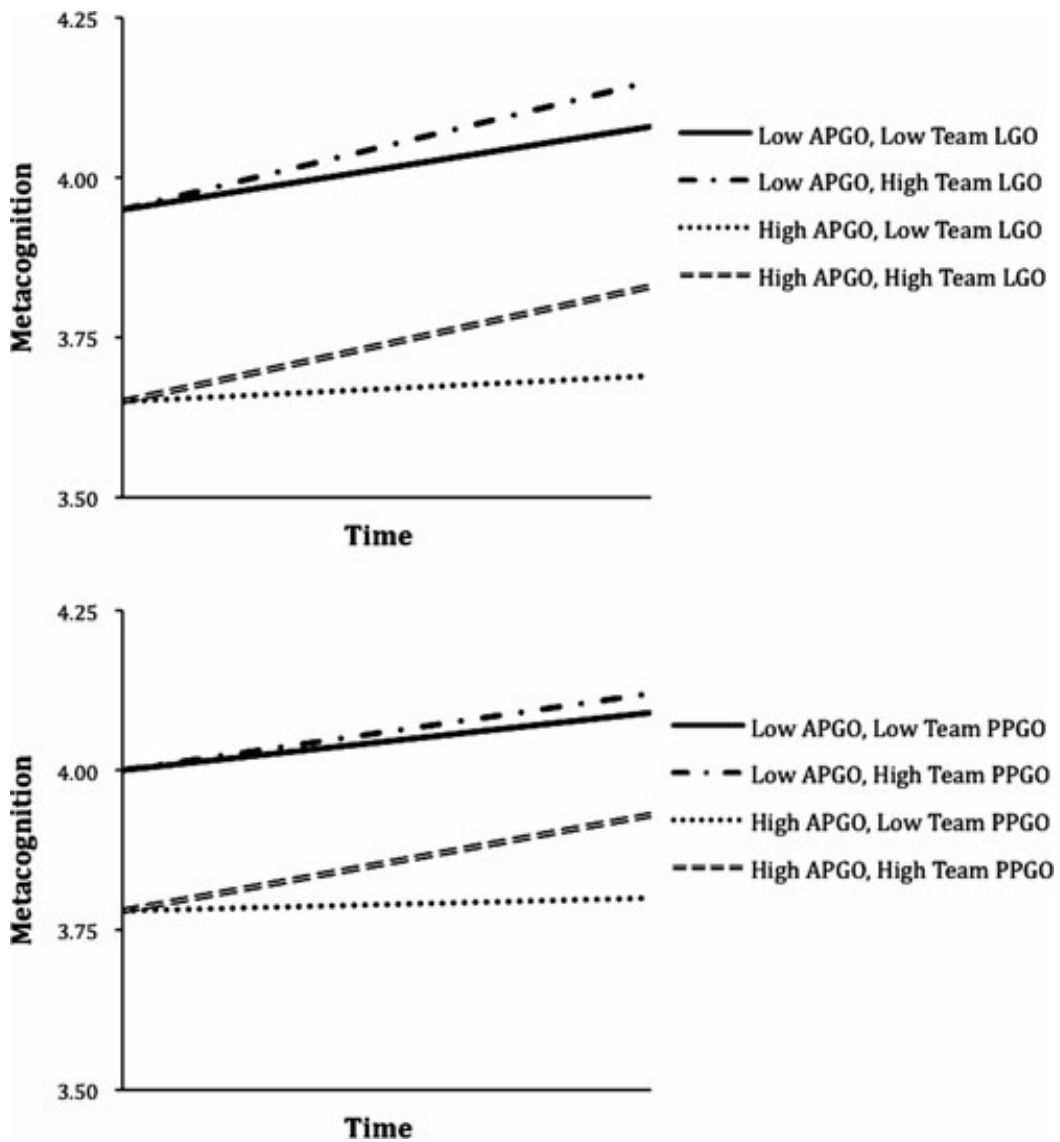

Figure 4: Cross-Level Moderation of APGO by Dissimilar Team Goal Orientation Compositions.

Figure 4 (bottom plot) indicates high team mean PPGO attenuated the negative effects of high individual-level APGO. ${ }^{6}$

\footnotetext{
${ }^{6}$ We tested dissimilarity with simple combination discrepancies. Dissimilarity could occur from other within-level interactions at the team-level (e.g., team mean PPGO $\times$ team mean APGO combination). We tested the possibility of team-level goal orientation composition interactions on the relationships between individual-level goal orientation and self-regulation. Of the 18 potential interactions from different team-level goal orientation composition profiles, only two were significant $(p<0.05)$ : team mean APGO $\times$ team mean PPGO $\times$ individual APGO, and team mean APGO $\times$ team mean PPGO $\times$ individual LGO, both on rates of self-efficacy. The inclusion of these team-level interaction terms did not change the sign or significance of the simpler team-level goal orientation composition parameters used to test Hypotheses 4-7.
} 
TABLE 6

Conditional Growth Model Results for Team-Level Outcomes

\begin{tabular}{|c|c|c|c|c|c|c|}
\hline \multirow[b]{2}{*}{ Fixed effects } & \multicolumn{2}{|c|}{ Team efficacy } & \multicolumn{2}{|c|}{ Team cooperation } & \multicolumn{2}{|c|}{$\begin{array}{c}\text { Team } \\
\text { decision making }\end{array}$} \\
\hline & Coefficient & $t$-ratio & Coefficient & $t$-ratio & Coefficient & $t$-ratio \\
\hline $\begin{array}{l}\text { Intercept (posttraining } \\
\text { status), } Y_{00}\end{array}$ & $4.049 * *$ & 64.121 & $3.971^{* *}$ & 89.569 & $41.510^{* *}$ & 15.689 \\
\hline $\begin{array}{l}\text { Time, } \\
Y_{10}\end{array}$ & 0.001 & 0.020 & $0.059 * *$ & 3.313 & $10.414^{* *}$ & 13.664 \\
\hline $\begin{array}{l}\text { Education level, } \\
\qquad Y_{20}\end{array}$ & 0.011 & 0.136 & $0.115^{*}$ & 1.697 & $4.726^{* *}$ & 2.240 \\
\hline $\begin{array}{l}\text { Self-efficacy variability, } \\
\qquad Y_{30}\end{array}$ & -0.125 & -0.941 & -0.164 & -1.508 & -4.720 & -1.155 \\
\hline $\begin{array}{l}\text { Metacognition } \\
\quad \text { variability, } \gamma_{40}\end{array}$ & $0.289 * *$ & 2.941 & 0.061 & 0.0512 & 4.992 & 1.057 \\
\hline $\begin{array}{l}\text { Average self-efficacy, } \\
\qquad Y_{50}\end{array}$ & $0.453^{* *}$ & 5.073 & $0.112^{*}$ & 1.747 & 7.719** & 1.994 \\
\hline $\begin{array}{l}\text { Average metacognition, } \\
y_{60}\end{array}$ & 0.113 & 1.209 & $0.168^{*}$ & 1.646 & $11.990 * *$ & 2.347 \\
\hline
\end{tabular}

Note. Degrees of freedom for $Y_{00}$ and $Y_{10}=63$, for $Y_{20} Y_{60}, d f=257$.

${ }^{*} p \leq 0.05,{ }^{* *} p \leq 0.01$ (one-tailed).

Hypotheses 8 and 9 predicted that average levels of self-efficacy and metacognition in teams are positively related to team-level outcomes. Table 6 presents results from the conditional growth models for team-level learning outcomes. The time-varying covariate of average self-efficacy was significantly related to team efficacy ( $Y_{50}=0.453, p<0.01$ ), team cooperation quality $\left(\gamma_{50}=0.112, p<0.05\right)$, and team strategic decisionmaking $\left(Y_{50}=7.72, p<0.01\right)$. The time-varying covariate of average metacognition was significantly related to team cooperation quality $\left(\gamma_{60}=0.168, p<0.05\right)$ and team strategic decision making $\left(Y_{60}=11.99\right.$, $p<0.01)$ but not to team efficacy $\left(Y_{60}=0.113, p>0.05\right)$. Taken together, these results are generally supportive of Hypotheses 8 and 9 . The predictors collectively explained $14 \%, 5 \%$, and $10 \%$ of the within-team variance in team efficacy, team cooperation quality, and team strategic decision making, respectively.

\section{Discussion}

This study introduces empirical data to an underdeveloped area of the team-training literature by exploring how dispositional goal orientation longitudinally impacts individual-level self-regulation. Our results show that goal orientation predicts changes in self-regulation within a team-training context. We further find that these individual-level relationships are moderated by the different contexts reflected in teams' 
goal orientation compositions. Finally, our results show that individuallevel self-regulation translates "upward" to multiple team-level outcomes. In the paragraphs that follow, we discuss our individual-level findings in relation to the goal orientation literature as well as several implications of our results for team-level outcomes. Potential areas for future research are proposed throughout.

Goal orientation studies that examine individual learning over time are far fewer in number than cross-sectional research. The findings from these studies are also much less consistent. For example, LGO has displayed mixed results with some research showing its positive influence on longitudinal performance (Yeo et al., 2009) and others failing to find effects on rates of change (Chen \& Mathieu, 2008). Similar equivocal results have been found for performance orientation, where it has sometimes been associated with lower rates of skill acquisition (Yeo \& Neal, 2004) and other times failed to display significant influences (Chen \& Mathieu, 2008). It should be noted, however, that previous studies have used Button et al.'s (1996) unitary operationalization of performance orientation, which most closely aligns with the conceptualization of PPGO (rather than APGO). Considering the nascent state of longitudinal goal orientation research and the mixed findings from extant studies, our study adds much needed empirical data to this domain. Our results show higher levels of LGO are related to greater rates of change in self-efficacy and metacognition, whereas higher levels of PPGO are associated with flatter change trajectories in such self-regulation. Findings also indicate that APGO carries a negative effect on self-regulation over time but only for levels of metacognition.

One possible explanation for the longitudinal effects we find across each type of dispositional goal orientation could be the nature of the training. Our study's context was team training where primary instructional emphasis is on team-level (vs. individual-level) functioning. Features of team-based training could accentuate the role of goal orientation. For instance, team training necessitates learning both taskwork and teamwork components, which likely serves to increase the overall complexity of the training. It stands to reason that increasing the complexity of training increases the likelihood of encountering obstacles during learning, and individuals higher in LGO are generally more effective in overcoming such challenges. One reason for this is that high LGO learners are better able to regulate their limited cognitive resources toward goal striving, which facilitates learning in demanding situations. Our results show high LGO individuals have steeper growth in self-regulation, which reflects successfully dealing with learning difficulties. Training complexity also appears to bring about the negative effects of PPGO on learning because such an orientation "shifts attention away from task activities when they 
are most needed" (p. 716; Yeo et al., 2009). Here, the inverse effects we find for PPGO suggest that high PPGO learners show lower rates of self-regulation throughout team training. More research that directly manipulates the complexity of team-training content is needed to better understand how complexity shapes longitudinal effects both within and across individuals.

Another feature of team training that could promote the effects of goal orientation on rates of learning is that it is likely to entail more social interactions than conventional individual-based training (Porter, 2008). For example, team settings likely increase the provision of performancerelated information, particularly normative feedback from other learners (e.g., fellow members or even other teams). Such information is especially salient for performance goal orientations because these directly pertain to the desire to either garner or avoid other-referenced performance feedback. The negative impact we find for performance goal orientations, whether PPGO or APGO, on the amount of metacognition in which learners engage over time supports the conjecture that focusing on demonstrating competence to others interferes with self-regulation. Considering the mixed findings for performance goal orientations from prior studies, it would be interesting for future research to experimentally compare the effects of goal orientation in team-based versus individual-based training. Another approach could be to capture more generic social features of training contexts (e.g., interdependence, social density, etc.) and test if these factors differentially moderate the influences of APGO and PPGO.

\section{Moderation by Team Goal Orientation Composition}

In team training, individual learning occurs within discrete team contexts. We argued that this creates differences in the social contexts associated with different teams and that one way to conceptualize such differences is by examining a team's goal orientation composition. To investigate the effects of team goal orientation compositions, we proposed two general situations: (a) parallelism, where the team's composition matches an individual's orientation, and (b) dissimilarity, when there is a mismatch between the team's composition and an individual's orientation. Overall, we found significant moderating effects across both of these situations. Our findings add to evidence from previous studies (e.g., LePine, 2005; Porter, 2005) and suggest that team goal orientation composition has predictive utility (Porter, 2008). Furthermore, our results suggest that team goal orientation composition reflects trait relevant features (Tett \& Guterman, 2000) for dispositional goal orientation, and consistent with motivated action theory (DeShon \& Gillespie, 2005), such situational features increase the salience of an individual's chronically active goals. 
Finally, when compared to other research showing particular deleterious or advantageous "profiles" of goal orientation (e.g., Bouffard et al., 1995; Pintrich, 2000), our study shows particular person-situation profiles are important when examining goal orientation effects.

We argued that parallel situations, where there is congruence between individuals' dispositional tendencies and the cues and consequences that are provided in the team context, accentuate the effects of goal orientation. Our results generally support this notion. For instance, results suggest that high LGO individuals in high mean LGO teams engage in greater rates of metacognition, whereas high APGO individuals in high mean APGO teams engage in lower rates of metacognition. Furthermore, high PPGO individuals in high mean PPGO teams appear to display less change in selfefficacy. Taken collectively, these findings demonstrate that congruence between an individual's chronically active goals and a team's context reflected by its composition will accentuate effects typically found in cross-sectional goal orientation research.

We also offered several hypotheses for cross-level moderation in dissimilar situations where an individual's dispositional tendencies are different from the team's composition. We expected dissimilar compositions to attenuate the positive effects of LGO. Although we did not find moderation by team mean PPGO, we did find moderation of individual LGO in high mean APGO teams. Interestingly, this moderation was in the opposite direction of our prediction, such that the positive effects of individual LGO on self-regulation over time were amplified in high mean APGO teams. It may be that in these situations, where other team members are exhibiting avoidance behaviors (e.g., failing to persist), high LGO individuals become even more self-referenced and focused on task mastery, both of which likely increase resources directed to self-regulation. Taken together, our findings highlight the resiliency of the benefits typically associated with high levels of LGO, which seem to occur regardless of team context.

Cross-level moderation results for PPGO suggest the negative effects of high PPGO on self-regulation are accentuated when these individuals are in high mean LGO and APGO teams. For example, findings show high PPGO individuals' self-efficacy diminishes when learning in high mean LGO teams. It could be that in these teams there is simply less opportunity for vicarious reinforcement aligning with what high PPGO individuals prefer, namely, examples of success via relative comparisons. When high PPGO individuals find themselves in high mean APGO teams, our results also indicate that they engage in less metacognition over time. This finding may suggest increased interference with self-regulation when high PPGO individuals are in contexts where other team members actively avoid the very information that they desire. 
As for the typical negative effects associated with APGO on learning, we expected that high mean LGO and PPGO team compositions would provide buffering learning contexts. Results provide some support for this prediction as high team mean LGO and PPGO lessened the negative effects of individual APGO on rates of metacognition but not self-efficacy. These findings imply that when other team members possess more approachoriented tendencies in a collective sense, it may counteract individuallevel avoidance tendencies. Interestingly, this also suggests that individual PPGO and team compositional PPGO exert different effects during team training (i.e., negative effects for individual PPGO and buffering effects for team mean PPGO).

\section{Team-Level Learning Outcomes}

Effective team performance entails collective cognitive, behavioral, and attitudinal activity (Salas \& Fiore, 2004), and effectively training teams necessitates that team members are individually engaged in the learning process (Ellis et al., 2003). With this in mind, we examined the degree to which individual-level self-regulation translates into gains in team-level cognitive, behavioral, and attitudinal outcomes. Our findings demonstrate that self-regulation has significant team-level consequences. By viewing individual-level self-regulation as team compositional variables, results show teams with members possessing higher levels of selfefficacy and metacognition perform more successfully on team-level outcomes over time.

Teams with higher average self-efficacy among members showed higher team efficacy and team cooperation quality, and more effective strategic decision making. That is, when team members are collectively more confident in their own capability to perform their tasks, they are subsequently more confident in their team's capability to accomplish objectives, perceive higher quality cooperation within their team, and are better able to make successful decisions as a team. Such findings highlight the influence of increasing individual-level self-efficacy to promote team-level outcomes and indicate the possibility of fostering positive upward "efficacy spirals" (Lindsley et al., 1995). However, although not specifically in team training, some research shows individual self-efficacy only matters to team performance when task interdependency is low (KatzNavon \& Erez, 2005). A possible reason for the difference in our study is that team training (vs. team task performance) necessitates a high level of interdependence in both taskwork and teamwork for effective learning to occur. As noted earlier, these team-training components likely increase complexity and could extend the effects of individual-level self-efficacy. Future research that manipulates the interdependence required for task 
completion could allow for a more thorough depiction of how self-efficacy operates in team training.

There is some debate in the team-training literature as to how to best design training, with some arguing for an initial focus on taskwork then on teamwork content (e.g., Salas, Burke, \& Canon-Bowers, 2002) and others for beginning with teamwork content (e.g., Ellis et al., 2005). Although our results cannot speak directly to this debate, the fact that our individual-level self-efficacy assessment was task specific in nature suggests that building team members' individual confidence to perform taskwork has important implications for team-level learning, including teamwork-related outcomes (i.e., cooperation quality). It would be interesting for ensuing research to investigate if task-specific self-efficacy displays similar positive effects for other teamwork-related outcomes such as backing-up behaviors. In addition, future studies could incorporate measures of teamwork-specific self-efficacy encompassing teamwork competencies known to comprise successful performance (see Cannon-Bowers et al., 1995).

Teams with higher average metacognition among members showed higher cooperation quality and more effective decision making in our study. These results indicate that when teams are composed of individuals who attend to and adjust their learning strategies, they subsequently show higher quality intrateam cooperation and are better able to make successful decisions. In team contexts, cooperation is a key factor related to team performance (Seers et al., 1995). Our results suggest that thinking about how you are performing as an individual in your team entails to some degree thinking about how successfully you are cooperating with fellow team members. Thus, teams with greater self-regulation among members are likely to reap higher quality cooperation. Along the same lines, our findings show that, when team members put more thought into their own learning, the team as a whole makes better decisions. These findings suggest individual-level self-regulation results in positive team-level behavioral and cognitive outcomes.

The positive relationships we find between average metacognition and team outcomes is congruent with the notion that increased cognition in teams in general can promote more effective functioning (Hinsz, 2004). It is important to note that we captured metacognition toward learning, which reflects the way individuals think about their own learning strategies. In team contexts other aspects of metacognition, such as thinking about how one's team processes information, are additionally important (Hinsz et al., 1997). This points to a need for future research exploring how individuallevel change in metacognition impacts development of team-level cognitions (e.g., team mental models, metamemory, implicit coordination) and ultimately team learning. Because team training requires a collective 
learning process, another potential research need pertains to how much individual-level metacognition is beneficial to team-level outcomes. That is, there may be a point of diminishing returns for the overall amount of individual-level metacognition within teams. Increased metacognition means more self-regulatory activity that focuses on one's own learning and thus, too much individually focused self-regulation might interfere with the resources needed for team-level learning.

\section{Limitations}

Several limitations of our study are important to delineate. First, team performance was only $24 \%$ of a participant's final course grade. In nonacademic settings, team performance could represent a larger proportion of, perhaps even the entire, criterion domain (e.g., surgical teams, flight or space crews). Thus, our study's results could be interpreted as conservative considering the higher level of motivation to perform that likely exists in nonacademic settings.

Second, the manner with which the team-based simulation operated did not allow for the identification of individual-level contributions. This precluded measuring additional individual-level learning outcomes. For example, the team as a whole made strategic decisions, and thus, the simulation did not produce individual-level decision-making data. Such data would allow for multilevel analysis depicting how team members' decision-making success or failure translates upward to team consequences. We also did not capture the particulars of between-person coordination (e.g., role definitions), which are potentially influential in team learning. Thus, we could not tease apart many of the complexities between individual-level and team-level learning trajectories and the intragroup processes that could shape such multilevel relationships.

Third, the simulation occurred over a 5-week period, and teams were formed and disbanded specifically for the training event. In the broader world of work, intact teams may enter new team training and existing intrateam dynamics are likely to impact both individual- and team-level outcomes. In addition, the extent to which team training varies in duration compared to this study could impact the generalization of our results. For example, some of the effects we found between individual-level learning and team-level outcomes may still be developing, and longer training periods may allow other relationships to emerge.

Fourth, our focus was on dispositional goal orientation at the individual level and at the team level as a composition variable. Theory and research suggest that other conceptualizations of goal orientation in teams are possible (e.g., collective goal orientation) and have important consequences for team functioning (see Porter, 2008; Porter, Webb, \& Gogus, 2010). In 
addition, goal orientation can be studied as a state-like variable shaped by situational factors (DeShon \& Gillespie, 2005). Team contexts then, could influence an individual's state goal orientation and the associated learning or performance outcomes over time. Thus, the effects we find for parallelism/dissimilarity between team goal orientation composition and dispositional goal orientation may or may not hold when examining individual-level state goal orientation. For instance, it is possible that over time an individual's state goal orientation converges to match the team's goal orientation composition or collective goal orientation.

Finally, our study did not include measures of learning transfer. Although previous research has demonstrated a link between transfer and self-efficacy and metacognition (Blume, Ford, Baldwin, \& Huang, 2010; Bransford, Brown, \& Cocking, 1999), it would be beneficial to directly examine the relationship between individual learning in a team-training context and the transfer of training content. Furthermore, directly testing the relationship between the team-level outcomes and transfer with regard to team performance would be particularly valuable.

Despite these limitations, our study's setting possesses several characteristics that bolster fidelity and generalizability. First, the training included components common to team training (i.e., taskwork and teamwork) and assessed multiple team-level outcomes. Second, the teamtraining simulation exercise provided a high fidelity context where teamwork and taskwork requirements are quite similar to those in a variety of organizational and occupational contexts. For example, participants worked together as a multifunctional "top management team" to run a simulated business, with decision consequences mirroring those in reallife financial, labor, and product markets. Finally, teams met weekly and made business decisions over a 5-week period. Although this duration may be atypical for many types of teams (e.g., production teams), this could be a similar life cycle for other team types (e.g., project teams, task forces, etc.).

\section{Implications for Practice}

Our results have a number of implications for team-training practice. Considering the ample empirical evidence for the influence of dispositional goal orientation on learning processes, the utility of incorporating such individual differences into training designs seems warranted. For example, short pretraining interventions aimed at buffering the deleterious effects associated with high PPGO or APGO could be provided to trainees with these dispositions. Such interventions could include those seeking to prime or boost self-regulatory outcomes like metacognition or self-efficacy (Kozlowski et al., 2001; Schmidt \& Ford, 2003). Individuals 
could also be assessed and provided targeted feedback on effective learning strategies in advance of training in order to maximize their in-training experience (Dierdorff, Surface, \& Brown, 2010). This latter approach may be particularly applicable to team training where self-awareness is a common component (Klein et al., 2009). Given the high monetary costs of training, it could be of great benefit to organizations to condense programs by designing team training in such a way as to encourage trainees to increase self-regulation at quicker rates.

Although we measured goal orientation as a disposition, goal orientation research demonstrates that it is possible to create situations or to design team-training scenarios to induce learning goals. Our results show that organizations needing to train their employees in teams will see benefits from having trainees with chronically active learning goals as opposed to other-referenced performance goals. This suggests perhaps that encouraging goals pertaining to task mastery during team training could increase rates of self-regulation. Likewise, discouraging or reducing trainees' focus on normative performance might also result in greater rates of self-regulation. These tactics are consistent with research showing that goal manipulations can affect self-regulation above and beyond dispositional goal orientation (Kozlowski \& Bell, 2006). Yet, our results also point to an important caveat for such interventions; namely, design efforts must account for the contexts created by team members' goal orientations. Our study highlights that team-training designs emphasizing approach-oriented behaviors at a more collective level (e.g., team-level mastery goals) may be beneficial for mitigating the negative impact of individual-level avoidance tendencies. This idea is also supported by research showing teams with approach orientations engage in better team planning and more effective performance (Mehta et al., 2009).

Finally, our team-level results suggest organizations that structure their employees into teams for training and accomplishing work can expect to see several team-level benefits from having higher average self-regulation among team members. In practice, it may be obvious to training specialists that increasing individual outcomes such as declarative and procedural knowledge would lead to team-level benefits; however, our results further imply that increasing individual-level self-regulation translates to favorable team-level outcomes. Considering the positive effects of selfregulation on individual-level learning and the efficacy of interventions to increase self-regulation (e.g., "adaptive guidance”; Schmidt \& Ford, 2003), efforts to promote self-regulation during team training are likely to yield both individual and team benefits. Furthermore, it seems likely training practitioners would be especially interested in efforts that affect outcomes like team strategic decision making, as this has direct benefits for the organization as a whole. 
In conclusion, our study demonstrates that goal orientation has meaningful consequences for self-regulation over time. We also find that the goal orientation of one's teammates is an important compositional variable affecting one's self-regulation during team training. Furthermore, levels of self-regulation account for differences in team-level outcomes. An implicit assumption underlying team-training practice is that for teams to learn, individual team members must learn as well. Yet, this assumption has not been the focus of much empirical inquiry. Our findings offer evidence showing that to neglect individual-level learning processes in team-training practice or team-training research is akin to ignoring a central force in the effectiveness of these learning initiatives. In conjunction with the few existing studies that have incorporated both individual-level and team-level examinations, our study further indicates the value of multilevel training research for uncovering the complexities of learning in team-training contexts.

\section{REFERENCES}

Ames C. (1992). Classrooms: Goals, structures, and student motivation. Journal of Educational Psychology, 84, 267-271.

Attenweiler WJ, Moore D. (2006). Goal orientations: Two, three, or more factors? Educational and Psychological Measurement, 66, 342-352.

Bandura A. (1982). Self-efficacy mechanisms in human agency. American Psychologist, 37, 122-147.

Bandura A. (1991). Social cognitive theory of self-regulation. Organizational Behavior and Human Decision Processes, 50, 248-287.

Bandura A. (1997). Self-efficacy: The exercise of control. New York, NY: Freeman.

Bell BS, Kozlowski SWJ. (2010). Toward a theory of learner-centered training design: An integrative framework of active learning. In Kozlowski S, Salas E (Eds.), Learning, training, and development in organizations (pp. 263-300). New York, NY: Routledge.

Bell ST. (2007). Deep-level composition variables as predictors of team performance: A meta-analysis. Journal of Applied Psychology, 92, 595-615.

Beier ME, Kanfer R. (2010). Motivation in training and development: A phase perspective. In Kozlowski S, Salas E (Eds.), Learning, training, and development in organizations (pp. 65-97). New York, NY: Routledge.

Blume BD, Ford JK, Baldwin TT, Huang JL. (2010). Transfer of training: A meta-analytic review. Journal of Management, 36, 1065-1105.

Bouffard T, Boisvert J, Vezeau C, Larouche C. (1995). The impact of goal orientation on self-regulation and performance among college students. British Journal of Educational Psychology, 65, 317-329.

Bransford J, Brown A, Cocking R. (1999). How people learn: Brain, mind, experience, and school. Washington, DC: National Academy Press.

Brown KG. (2001). Using computers to deliver training: Which employees learn and why? Personnel Psychology, 54, 271-296.

Button SB, Mathieu JE, Zajac DM. (1996). Goal orientation in organizational research: A conceptual and empirical foundation. Organizational Behavior and Human Decision Processes, 67, 26-48. 
Cannon-Bowers JA, Salas E. (2001). Reflections on shared cognition. Journal of Organizational Behavior, 22, 195-202.

Cannon-Bowers JA, Salas E, Milham LM. (2003). The transfer of team training: Recommendations for practice. In Holton EF, Baldwin TT (Eds.), Improving learning transfer in organizations (pp. 195-226). San Francisco, CA: Jossey-Bass.

Cannon-Bowers JA, Tannenbaum SI, Salas E, Volpe CE. (1995). Defining team competencies and establishing team training requirements. In Guzzo R, Salas E (Eds.), Team effectiveness and decision making in organizations (pp. 333-380). San Francisco, CA: Jossey-Bass.

Carver CS, Scheier MF. (1998). On the self-regulation of behavior. Cambridge, UK: Cambridge University Press.

Chan D. (1998). Functional relationships among constructs in the same content domain at different levels of analysis: A typology of composition models. Journal of Applied Psychology, 83, 234-246.

Chen G, Gully SM, Whiteman JA, Kilcullen RN. (2000). Examination of relationships among trait-like individual differences, state-like individual differences, and learning performance. Journal of Applied Psychology, 85, 835-847.

Chen G, Klimoski RJ. (2007). Training and development of human resources at work: Is the state of our science strong? Human Resource Management Review, 17, 180-190.

Chen G, Mathieu JE. (2008). Goal orientation dispositions and performance trajectories: The roles of supplementary and complementary situational inducements. Organizational Behavior and Human Decision Processes, 106, 21-38.

Chen G, Thomas BA, Wallace JC. (2005). A multilevel examination of the relationships among training outcomes, mediating regulatory processes, and adaptive performance. Journal of Applied Psychology, 90, 827-841.

Colquitt JA, LePine JA, Noe RA. (2000). Toward an integrative theory of training motivation: A meta-analytic path analysis of 20 years of research. Journal of Applied Psychology, 85, 678-707.

Day E, Arthur W, Bell ST, Edwards BD, Bennett W, Mendoza JL, Tubre TC. (2005). Ability-based pairing strategies in the team-based training of a complex skill: Does the intelligence of your training partner matter? Intelligence, 33, 39-65.

Day E, Yeo S, Radosevich DJ. (2003, April). Comparing two- and three-factor models of goal orientation: A meta-analysis. Paper presented at the 18th Annual Conference of the Society for Industrial and Organizational Psychology, Orlando, FL.

DeShon RP, Gillespie JZ. (2005). A motivated action theory account of goal orientation. Journal of Applied Psychology, 90, 1096-1127.

DeShon RP, Kozlowski SWJ, Schmidt AM, Milner KR, Weichmann D. (2004). A multiplegoal, multilevel model of feedback effects on the regulation of individual and team performance. Journal of Applied Psychology, 89, 1035-1056.

Diener CI, Dweck CS. (1978). An analysis of learned helplessness: Continuous changes in performance, strategy, and achievement conditions following failure. Journal of Personality and Social Psychology, 36, 451-462.

Dierdorff EC, Bell ST, Belohlav JA. (2011). The power of "we”: Effects of psychological collectivism on team performance over time. Journal of Applied Psychology, 96, 247-262.

Dierdorff EC, Surface EA, Brown KG. (2010). Frame-of-reference training effectiveness: Effects of goal orientation and self-efficacy on affective, cognitive, skill-based, and transfer outcomes. Journal of Applied Psychology, 95, 1181-1191.

Dragoni L. (2005). Understanding the emergence of state goal orientation in organizational work groups: The role of leadership and multilevel climate perceptions. Journal of Applied Psychology, 90, 1084-1095. 
Dweck CS. (1986). Motivational processes affecting learning. American Psychologist, 41, 1041-1048.

Dweck CS, Leggett EL. (1988). A social-cognitive approach to motivation and personality. Psychological Review, 95, 256-273.

Elliot AJ, Church MA. (1997). A hierarchical model of approach and avoidance achievement motivation. Journal of Personality and Social Psychology, 72, 218232.

Elliot AJ, Harackiewicz JM. (1996). Approach and avoidance achievement goals and intrinsic motivation: A mediational analysis. Journal of Personality and Social Psychology, 70, 461-475.

Elliot AJ, McGregor HA. (1999). Test anxiety and the hierarchical model of approach and avoidance achievement motivation. Journal of Personality and Social Psychology, 76, 628-644.

Elliot AJ, McGregor HA. (2001). A $2 \times 2$ achievement goal framework. Journal of Personality and Social Psychology, 80, 501-519.

Elliot AJ, McGregor HA, Gable SL. (1999). Achievement goals, study strategies, and exam performance: A mediational analysis. Journal of Educational Psychology, 9, 549-563.

Elliot AJ, Shell M, Henry KB, Maier M. (2005). Achievement goals, performance contingencies, and performance attainment: An experimental test. Journal of Educational Psychology, 97, 630-640.

Ellis APJ, Bell BS, Ployhart RE, Hollenbeck JR, Ilgen DR. (2005). An evaluation of generic teamwork skills with action teams: Effects on cognitive and skill-based outcomes. Personnel Psychology, 58, 641-672.

Ellis APJ, Hollenbeck JR, Ilgen DR, Porter COLH, West BJ, Moon H. (2003). Team learning: Collectively connecting the dots. Journal of Applied Psychology, 88, 821-835.

Fisher SL, Ford JK. (1998). Differential effects of learner effort and goal orientation on two learning outcomes. Personnel Psychology, 51, 397-420.

Flavell JH. (1979). Metacognition and cognitive monitoring: A new area of cognitivedevelopmental inquiry. American Psychologist, 34, 906-911.

Gully SM, Chen G. (2010). Individual differences, aptitude-treatment interactions, and learning. In Kozlowski S, Salas E (Eds.), Learning, training, and development in organizations (pp. 3-64). New York, NY: Routledge.

Gully SM, Incalcaterra KA, Joshi A, Beaubein JM. (2002). A meta-analysis of teamefficacy, potency, and performance: interdependence and level of analy- sis as moderators of observed relationships. Journal of Applied Psychology, 87, 819-832.

Guzzo RA, Dickson MW. (1996). Teams in organizations: Recent research on performance and effectiveness. Annual Review of Psychology, 47, 307-338.

Hackman JR. (1987). The design of work teams. In Lorsch JW (Ed.), Handbook of organizational behavior (pp. 315-342). Englewood Cliffs, NJ: Prentice Hall.

Hackman JR. (1992). Group influences on individuals in organizations. In Dunnette MD, Hough LM (Eds.), Handbook of industrial organizational psychology (Vol. 3, pp. 199-267). Palo Alto, CA: Consulting Psychology Press.

Harackiewicz JM, Barron KE, Tauer JM, Carter SM, Elliot AJ. (2000). Predicting success in college: A longitudinal study of achievement goals and ability measures as predictors of interest and performance from freshman year through graduation. Journal of Educational Psychology, 94, 562-575.

Hinsz VB. (2004). Metacognition and mental models in groups: An illustration with metamemory of group recognition memory. In Salas E, Fiore SM (Eds.), Team 
cognition: Understanding the factors that drive process and performance (pp. 3358). Washington, DC: APA.

Hinsz VB, Tindale RS, Vollrath DA. (1997). The emerging conceptualization of groups as information processors. Psychological Bulletin, 121, 43-64.

Ilgen DR, Hollenbeck JR, Johnson M, Jundt D. (2005). Teams in organizations: From input-process-output models to IMOI models. Annual Review of Psychology, 56, $517-543$.

Johns G. (2006). The essential impact of context on organizational behavior. Academy of Management Review, 31, 386-408.

Kanfer R, Ackerman PL. (1989). Motivation and cognitive abilities: An integrative/aptitudetreatment approach to skill acquisition. Journal of Applied Psychology, 74, 657-690.

Karoly P. (1993). Mechanisms of self-regulation: A systems view. Annual Review of Psychology, 44, 23-52.

Katz-Navon TY, Erez M. (2005). When collective- and self-efficacy affect team performance. Small Group Research, 36, 437-465.

Klein C, DiazGranados D, Salas E, Le H, Burke CS, Lyons R, Goodwin GF. (2009). Does team building work? Small Group Research, 40, 181-222.

Kozlowski SWJ, Bell BS. (2006). Disentangling achievement orientation and goal setting: Effects of self-regulatory processes. Journal of Applied Psychology, 91, 900-916.

Kozlowski SWJ, Gully SM, Salas E, Cannon-Bowers JA. (1996). Team leadership and development: Theory, principles, and guidelines for training leaders and teams. In Beyerlein M, Johnson D, Beyerlein S (Eds.), Advances in interdisciplinary studies of work teams: Team leadership (Vol. 3, pp. 253-291). Greenwich, CT: JAI Press.

Kozlowski SWJ, Klein KJ. (2000). A multilevel approach to theory and research in organizations: Contextual, temporal, and emergent processes. In Kozlowski S, Klein K (Eds.), Multilevel theory, research, and methods in organizations: Foundations, extensions, and new directions (pp. 3-90). San Francisco, CA: Jossey-Bass.

Kozlowski SWJ, Toney RJ, Mullins ME, Weissbein DA, Brown KG, Bell BS. (2001). Developing adaptability: A theory for the design of integrated-embedded training systems. In Salas E (Ed.), Advances in human performance and cognitive engineering research (Vol. 1, pp. 59-123). Amsterdam: JAI/Elsevier Press.

LePine JA. (2005). Adaptation of teams in response to unforeseen change: Effects of goal difficulty and team composition in terms of cognitive ability and goal orientation. Journal of Applied Psychology, 90, 1153-1167.

Lindsley DH, Brass DJ, Thomas JB. (1995). Efficacy-performance spirals: A multilevel perspective. Academy of Management Review, 20, 645-678.

Mathieu JE, Schulze W. (2006). The influence of team knowledge and formal plans on episodic team process-performance relationships. Academy of Management Journal, 49, 605-619.

Mehta A, Feild HS, Armenakis AA, Mehta N. (2009). Team goal orientation and team performance: The mediation of team planning. Journal of Management, 35, 10261046.

Mohammed S, Hamilton K, Lim A. (2008). The incorporation of time in team research: Past, current, and future. In Salas E, Goodwin G, Burke C (Eds.), Team effectiveness in complex organizations: Cross disciplinary perspectives and approaches (pp. 317344). Mahwah, NJ: Erlbaum.

Morgeson FP, Dierdorff EC. (2010). Job and work analysis: From technique to theory. In Zedeck S (Ed.), APA Handbook of industrial and organizational psychology (Vol. 2, pp. 3-41). Washington, DC: APA. 
Payne SC, Youngcourt SS, Beaubien JM. (2007). A meta-analytic examination of the goal orientation nomological net. Journal of Applied Psychology, 92, 128-150.

Pintrich PR. (2000). Multiple goals, multiple pathways: The role of goal orientation in learning and achievement. Journal of Educational Psychology, 92, 544-555.

Porath CL, Bateman TS. (2006). Self-regulation: From goal orientation to job performance. Journal of Applied Psychology, 91, 185-192.

Porter COLH. (2005). Goal orientation: Effects on backing up behavior, performance, efficacy, and commitment in teams. Journal of Applied Psychology, 90, 811-818.

Porter COLH. (2008). A multilevel, multiconceptualization perspective of goal orientation in teams. In Sessa VI, London M (Eds.), Work group learning: Understanding, improving, and assessing how groups learn in organizations (pp. 149-173). New York, NY: Erlbaum/Taylor and Francis.

Porter COLH, Webb JW, Gogus CI. (2010). When goal orientations collide: Effects of learning and performance orientation on team adaptability in response to workload imbalance. Journal of Applied Psychology, 95, 935-943.

Raudenbush SW, Bryk AS. (2002). Hierarchical linear models: Applications and data analysis methods. Thousand Oaks, CA: Sage.

Raudenbush SW, Bryk AS, Cheong YF, Congdon R. (2004). HLM 6: Hierarchical linear and nonlinear modeling. Lincolnwood, IL: Scientific Software International, Inc.

Rawsthorne LJ, Elliot AJ. (1999). Achievement goal and intrinsic motivation: A metaanalytic review. Personality and Social Psychology Review, 3, 326-344.

Salas E, Burke CS, Cannon-Bowers JA. (2002). What we know about designing and delivering team training: Tips and guidelines. In Kraiger K (Ed.), Creating, implementing, and managing effective training and development: State-of-the-art lessons for practice (pp. 234-259). San Francisco, CA: Jossey-Bass.

Salas E, DiazGranados D, Klein C, Burke CS, Stagl KC, Goodwin GF, Halpin SH. (2008). Does team training improve team performance? A meta-analysis. Human Factors, 50, 903-933.

Salas E, Fiore SM. (2004). Why team cognition? In Salas E, Fiore S (Eds.), Team cognition: Understanding the factors that drive process and performance (pp. 3-8). Washington, DC: APA.

Schmidt AM, Ford JK. (2003). Learning within a learner control training environment: The interactive effects of goal orientation and metacognitive instruction on learning outcomes. Personnel Psychology, 56, 405-429.

Schraw G, Horn C, Thorndike-Christ T, Bruning R. (1995). Academic goal orientations and student classroom achievement. Contemporary Educational Psychology, 20, 359-368.

Schunk DH. (1990). Goal setting and self-efficacy during self-regulated learning. Educational Psychologist, 25, 71-86.

Seers A. (1989). Team-member exchange quality: A new construct for role-making research. Organizational Behavior and Human Decision Processes, 43, 118-135.

Seers A, Petty MM, Cashman JF. (1995). Team-member exchange under team and traditional management: A naturally occurring quasi-experiment. Group \& Organization Management, 20, 18-38.

Seijts GH, Latham GP, Tasa K, Latham BW. (2004). Goal setting and goal orientation: An integration of two different yet related literatures. Academy of Management Journal, 47, 227-239.

Terborg JR. (1981). Interactional psychology and research on human behavior in organizations. Academy of Management Review, 6, 569-576. 
Tett RP, Burnett DD. (2003). A personality trait-based interactionist model of job performance. Journal of Applied Psychology, 88, 500-517.

Tett RP, Guterman HA. (2000). Situation trait relevance, trait expression, and crosssituational consistency: Testing a principle of trait activation. Journal of Research in Personality, 34, 397-423.

Turner ME. (2001). Groups at work: Theory and research. Mahwah, NJ: Erlbaum.

VandeWalle D. (1997). Development and validation of a work domain goal orientation instrument. Educational and Psychological Measurement, 57, 995-1015.

VandeWalle D, Cron WL, Slocum JW, Jr. (2001). The role of goal orientation following performance feedback. Journal of Applied Psychology, 86, 629-640.

VandeWalle D, Cummings LL. (1997). A test of the influence of goal orientation on the feedback seeking process. Journal of Applied Psychology, 82, 390-400.

Weiss HM. (1990). Learning theory and industrial and organizational psychology. In Dunnette MD, Hough LM (Eds.), Handbook of industrial and organizational psychology (Vol. 1, 2nd ed., pp. 171-221). Palo Alto, CA: Consulting Psychologists Press.

Yeo G, Loft S, Xiao T, Kiewitz C. (2009). Goal orientations and performance: Differential relationships across levels of analysis and as a function of task demands. Journal of Applied Psychology, 94, 710-726.

Yeo G, Neal A. (2004). A multilevel analysis of the relationship between effort and performance: Effects of ability, conscientiousness, and goal orientation. Journal of Applied Psychology, 89, 231-247.

Yeo G, Neal A. (2006). An examination of the dynamic relationship between self-efficacy and performance across levels of analysis and levels of specificity. Journal of Applied Psychology, 91, 1088-1101.

Zimmerman BJ. (1990). Self-regulated learning and academic achievement: An overview. Educational Psychologist, 25, 3-17.

Zimmerman BJ, Kitsantas A. (1997). Developmental phases in self-regulation: Shifting from process goals to outcome goals. Journal of Educational Psychology, 89, 29-36. 